\title{
Vibration Behavior and Dynamic Stress of Runners of Very High Head Reversible Pump-turbines
}

\author{
Hiroshi Tanaka \\ Hydraulic Machinery, Toshiba Corporation (Retired) \\ Yokohama, Japan \\ hitanak@syd.odn.ne.jp
}

\begin{abstract}
In the development of very high head pumped storage projects, one of the critical problems is the strength of pumpturbine runners. Data obtained by stress measurements of high head pump-turbine runners indicated that dynamic stress due to the vibration of runner might be detrimental, possibly to cause fatigue failure, if the runner were designed without proper consideration on its dynamic behaviour. Numerous field stress measurements of runners and model tests conducted with hydrodynamic similarity revealed that the hydraulic excitation force developed by the interference of rotating runner blades with guide vane wakes sometimes would induce such heavy vibration of runner. Theoretical and experimental investigations on both the hydraulic excitation force and the natural frequencies of runner have been conducted to explore this forced vibration problem.
\end{abstract}

Keywords: Vibration behavior, Dynamic stress, Hydraulic excitation force, Vibration mode, Prototype head model test

\section{Introduction}

Structural design of runner is one of key technologies in the design work of high head pump-turbines as well as hydraulic design.

In 1975, when the working stress of the runner of $500 \mathrm{~m}$ head reversible pump-turbine at Ohira Power Station was measured during the turbine start in its commissioning test, it was found that the amplitude of the alternating stress of the runner showed an increase at about $90 \%$ speed. This was apparently caused by some resonance of the runner at the speed.

Similar phenomena were observed in the stress measurements on other $500 \mathrm{~m}$ class pump-turbines conducted later. It was observed also the magnitude of the alternating stress reached \pm 50 to $60 \mathrm{MPa}$ when the resonance took place near the rated speed. Under such high alternating stress, very minor casting defect may trigger growth of fatigue crack as shown on Fig. 21.

In Toshiba Hydraulic Research Laboratory, extensive studies on this phenomenon have been carried out since then by means of prototype head model tests which met both hydraulic and dynamic similarity (hydrodynamic similarity). Earlier studies both theoretical and experimental revealed the following findings.

(1) The vibration was caused by the excitation due to hydraulic interference between runner blades and guide vanes.

(2) The natural frequency of the runner installed in water became less than $50 \%$ of that in air due to the added mass effect of the water.

(3) If the runner is designed inadequately, resonance may occur near the rated speed and the magnitude of vibration stress may reach a level to cause fatigue failure of the runner.

(4) Vibration dominantly observed on stationary parts of very high head pump-turbines was also induced by the same origin; namely, the hydraulic interference between runner and guide vanes.

This article describes the characteristics of this specific vibration caused by the hydraulic interference between runner blades and guide vanes, such as frequencies, modes of the vibration, added mass effect of the water and influences of various design factors.

\section{Interference of Blade Cascade between Runner and Guide Vanes}

In case of high head pump-turbines, the thickness of guide vanes is large. It develops large excitation force acting on runner

Received June 2 2011; revised June 7 2011; accepted for publication June 20 2011: Review conducted by Prof. Yoshinobu Tsujimoto. (Paper number R11013J)

Corresponding author: Hiroshi Tanaka, hitanak@syd.odn.ne.jp

This paper was presented at the 15th IAHR Symposium in 1990 as a Special Lecture. It was invited to IJFMS considering its permanent significance. 
blades, when the blades pass across their wakes.

The hydraulic force caused by this interference gives regular periodic excitation to the runner and induces its vibration.

It consists of various harmonics with a principal frequency of $\left(Z_{g} \cdot N\right) \mathrm{Hz}$ and its high order harmonics of $\left(n \cdot Z_{g} \cdot N\right) \mathrm{Hz}$, where $Z_{g}$ is the number of guide vanes, $N$ is the rotational speed of runner (rps) and $n$ is an arbitrary integer.

The interference between runner blades and guide vanes occurs at a certain phase shift and time lag around the periphery of the runner. The phase lag is determined by the combination of $Z_{g}$ and the number of runner blades, $Z_{r}$.

Figure 1 shows an example of such phase lag in case of $Z_{g}=20$ and $Z_{r}=6$.

$$
\begin{aligned}
& \theta_{\mathrm{r}}: \text { angle of runner rotation } \\
& \theta_{\mathrm{h}}: \text { angle of travelling of hydraulic impacts in stationary coordinates } \\
& \phi_{\mathrm{h}}: \text { : }
\end{aligned}
$$

$\sum^{3}$ : hydraulic impacts due to interference between runner blades and guide vanes
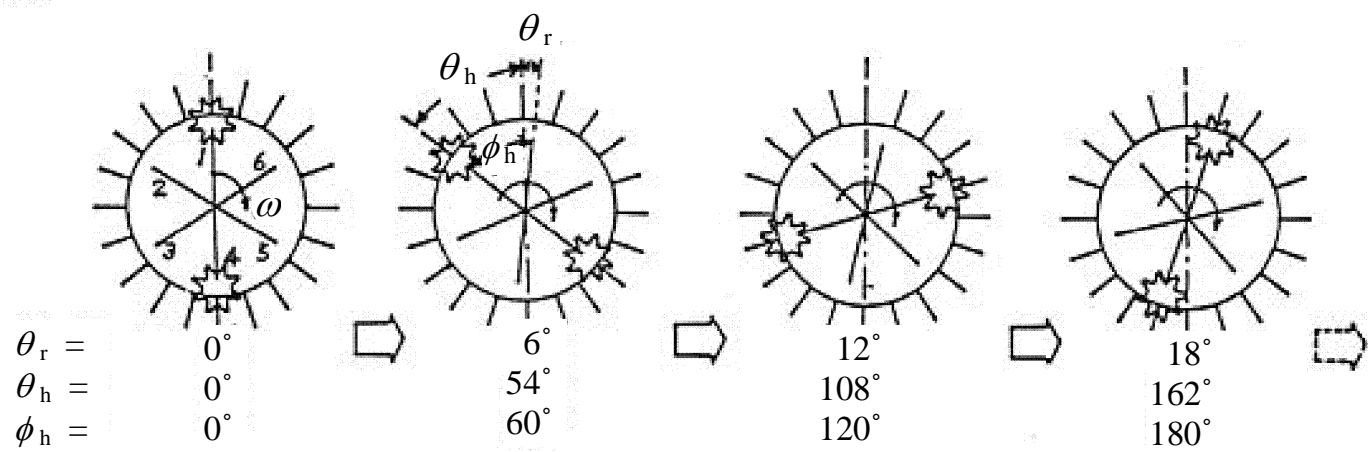

Fig. 1 Hydraulic interference of runner blades and guide vane

As indicated in Fig. 1, runner blades 1 and 4 are first excited by interference with guide vane wakes and then blades 2 and 5 . In this case, runner blades 1 and 4 or 2 and 5 are excited in phase and induce a vibration having a mode with 2 diametrical nodes. In addition, the nodes of this vibration mode move around the runner in opposite direction to the runner rotation. In this manner, the excitation force caused by the interference between runner blades and guide vanes induces certain modes of vibration, which have specific number of diametrical nodes turning around the axis of runner. Examples of modes with various numbers of diametrical nodes are shown in Fig. 2.

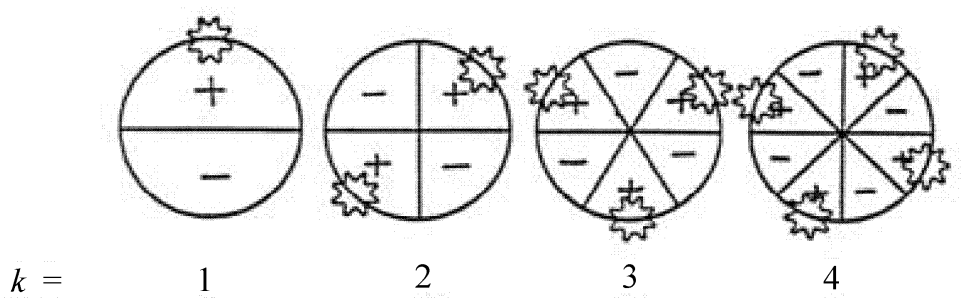

Fig. 2 Vibration modes with $k$ diametrical nodes

The number of diametrical nodes $k$ is given by the combination of $Z_{g}$ and $Z_{r}$ as stated below. [1]

The frequency of the $n$-th harmonic of the hydraulic excitation exerted on runner due to the interference is given as follows.

$$
f_{r}=n \cdot Z g \cdot N
$$

The runner is forced to vibrate at the above frequencies. If we denote the vibration with $k$ diametrical nodes by $X_{k}$, the vibration of runner with the frequency of $f_{r}$ is expressed by the following equation as a sum of the modes with various numbers of diametrical nodes.

$$
X=\sum_{k=0}^{\infty} X_{k}
$$

Figure 3 illustrates schematically the relationship between runner blades and guide vanes. The vibration of runner consisting of $k$ diametrical node modes which is induced by the excitation acting on blade $R(1)$ is expressed as follows;

$$
X_{k 1}=A(\cos k \phi)\left(\sin 2 \pi \cdot f_{r} \cdot t\right)
$$

In the same way, the vibration of runner excited by the $i$-th blade, $R(i)$, is expressed as follows, considering the time lag necessary for the blade $R(i)$ to reach the $j$-th guide vane, $S(j)$.

$$
X_{k i}=A\left[\cos k\left(\phi-\phi_{i}\right)\right]\left\{\left(\sin 2 \pi \cdot f_{r}\left[t-\left(\theta_{j}-\phi_{i}\right) / 2 \pi \cdot N\right]\right\}\right.
$$

where, $\phi_{i}$ is the angular coordinate of the location of the blade $R(i)$ in the coordinates fixed to runner and written as follows;

$$
\phi_{i}=2 \pi(i-1) / Z_{r}
$$

Also, $\theta_{j}$ represents the location of the guide vane $S(j)$ on the stationary coordinates, which is written as follows.

$$
\theta_{j}=2 \pi(j-1) / Z_{g}
$$




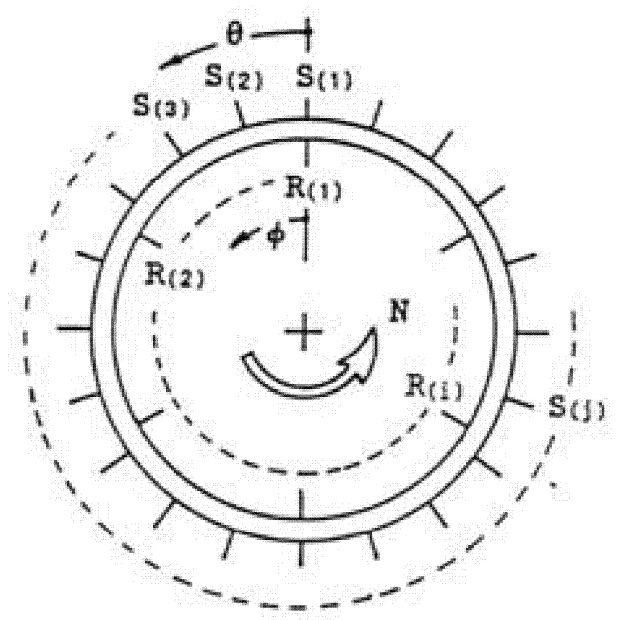

Fig. 3 Angular coordinates on runner and on stationary part

By substituting Eqs. (1) and (6) into Eq. (4),

$$
X_{k i}=A\left[\cos k\left(\phi-\phi_{i}\right)\right]\left[\sin 2 \pi \cdot f_{r}\left(t+\phi_{i} / 2 \pi \cdot N\right)\right]
$$

Therefore, the vibration of $k$ diametrical nodes excited on a runner having $Z_{r}$ blades is given as follows;

$$
X_{k}=\sum_{i=1}^{Z_{r}} X_{k i}=\sum_{i=1}^{Z_{r}} A\left[\cos k\left(\phi-\phi_{i}\right)\right]\left[\sin 2 \pi \cdot f_{r}\left(t+\phi_{i} / 2 \pi \cdot N\right)\right]
$$

By substituting Eq. (5) into Eq. (8),

$$
\begin{aligned}
X_{k}=(A / 2) \sum_{i=1}^{Z_{r}}\left\{\operatorname { s i n } \left[\left(2 \pi \cdot f_{r} \cdot t-k \phi\right)\right.\right. & \left.+2 \pi(i-1)\left(n \cdot Z_{g}+k\right) / Z_{r}\right] \\
& \left.+\sin \left[\left(2 \pi \cdot f_{r} \cdot t+k \phi\right)+2 \pi(i-1)\left(n \cdot Z_{g}-k\right) / Z_{r}\right]\right\}
\end{aligned}
$$

This equation represents the superposition of many waves with different phase. By carrying out the summation, we obtain,

$$
\begin{aligned}
X_{k}=(A / 2)\left\{C _ { 1 } \operatorname { s i n } \left[\left(2 \pi \cdot f_{r} \cdot t-k \phi\right)\right.\right. & \left.+\pi\left(Z_{r}-1\right)\left(n \cdot Z_{g}+k\right) / Z_{r}\right] \\
& \left.+C_{2} \sin \left[\left(2 \pi \cdot f_{r} \cdot t+k \phi\right)+\pi\left(Z_{r}-1\right)\left(n \cdot Z_{g}-k\right) / Z_{r}\right]\right\}
\end{aligned}
$$

where,

$$
\begin{aligned}
& C_{1}=\left[\sin \pi\left(n \cdot Z_{g}+k\right)\right] /\left[\sin \pi\left(n \cdot Z_{g}+k\right) / Z_{r}\right] \\
& C_{2}=\left[\sin \pi\left(n \cdot Z_{g}-k\right)\right] /\left[\sin \pi\left(n \cdot Z_{g}-k\right) / Z_{r}\right]
\end{aligned}
$$

The first term on the right of Eq. (10) represents the progressive wave excited on the runner and the second term represents the retrogressive wave. The numerators of the constants, $C_{1}$ and $C_{2}$, in the terms of vibration amplitudes is always zero since ( $n \cdot Z_{g} \pm k$ ) is integer. Therefore, if the denominators of $C_{1}$ and $C_{2}$, which are $\sin \left[\pi\left(n \cdot Z_{g} \pm k\right) / Z_{r}\right]$, are not zero, the value of $X_{k}$ given by Eq. (10) becomes zero and the vibration with $k$ diametrical nodes is not excited on the runner. On the contrary, the vibration with $k$ diametrical nodes can be excited only in case the denominators of $C_{1}$ and $C_{2}$ are zero. This is given by the following condition.

where, $m$ is an arbitrary integer.

$$
n \cdot Z_{g} \pm k=m \cdot Z_{r}
$$

Under this condition (13), the values of $C_{1}$ and $C_{2}$ are indeterminate. They are obtained by computing the limit value of [ $\sin \pi\left(Z_{r} \cdot x\right) / \sin \pi \cdot x$ ] when $x$ converges to $m$. The value of $C_{1}$ or $C_{2}$, thus obtained, is $\pm Z_{r}$, where plus sign is for even numbers of $m\left(Z_{r}-1\right)$ and minus sign is for odd numbers of $m\left(Z_{r}-1\right)$.

Therefore, when Eq. (13) is satisfied, Eq. (10) becomes as follows;

$$
X_{k}=(A / 2) Z_{r}\left[\sin \left(2 \pi \cdot f_{r} \cdot t-k \phi\right)+\sin \left(2 \pi \cdot f_{r} \cdot t+k \phi\right)\right]
$$

If the above vibration is viewed from the stationary coordinates, it is expressed as follows by substituting $\phi=\theta-2 \pi N \cdot t$.

$$
\begin{aligned}
X_{k} & =(A / 2) Z_{r}\left\{\sin \left[2 \pi\left(f_{r}+k \cdot N\right) t-k \theta\right]+\sin \left[2 \pi\left(f_{r}-k \cdot N\right) t+k \theta\right]\right\} \\
& =(A / 2) Z_{r}\left[\sin \left(2 \pi \cdot f_{s} \cdot t-k \theta\right)+\sin \left(2 \pi \cdot f_{s} \cdot t+k \theta\right)\right]
\end{aligned}
$$

where,

$$
f_{s}=f_{r} \pm k \cdot N=\left(n \cdot Z_{g} \pm k\right) N=m \cdot Z_{r} \cdot N
$$

Namely, the vibration is observed from the stationary coordinates as if it were vibrating at the frequencies $\left(m \cdot Z_{r} \cdot N\right) \mathrm{Hz}$.

Although the above theoretical study has been made on the vibration of runner, the same logic can be applied to the mode of the pressure fluctuation between runner and guide vanes caused by their interference. Therefore, the frequencies given by Eq. (16) also represent the dominant frequencies of the vibration induced at the stationary parts of pump-turbines.

As stated before, the vibration modes induced by this hydraulic interference turn around the axis of runner. The angular velocity of the modes is $\pm\left(f_{r} / k\right) \mathrm{Hz}$ against the rotating coordinates and $\pm\left(f_{s} / k\right) \mathrm{Hz}$ against stationary coordinates. The plus sign indicates the mode turning in the same direction of runner rotation and the minus sign the opposite. 
The resonance of a runner takes place when the frequency $f_{r}$ coincides with the natural frequency of the runner having $k$ diametrical nodes.

The relations given by Eq. (13) for the examples of $Z_{g}=20$ with variants of $Z_{r}=6$ and $Z_{r}=7$ are shown in Table 1 .

Table 1 Frequency and mode of hydraulic interference for various combinations of $Z_{g}$ and $Z_{r}$

\begin{tabular}{|c|c|c|c|c|c|}
\hline \multicolumn{3}{|c|}{$Z_{g}=20, Z_{r}=6$} & \multicolumn{3}{c|}{$Z_{g}=20, Z_{r}=7$} \\
\hline$f_{r}=Z_{g} \cdot N$ & $f_{s}=m \cdot Z_{r} \cdot N$ & $k$ & $f_{r}=Z_{g} \cdot N$ & $f_{s}=m \cdot Z_{r} \cdot N$ & $k$ \\
\hline \multirow{5}{*}{$20 N$} & $6 N$ & -14 & & $7 N$ & -13 \\
& $12 N$ & -8 & & $14 N$ & -6 \\
& $18 N$ & -2 & $20 N$ & $21 N$ & +1 \\
& $24 N$ & +4 & & $28 N$ & +8 \\
& $30 N$ & +10 & & $35 N$ & +15 \\
\hline
\end{tabular}

\section{Vibration Behavior of Prototype Runners}

When the hydraulic excitation is imposed, the flat parts of both runner crown and band as indicated by the shaded area in Fig. 4 vibrate. Consequently, vibration stress is concentrated at the fillets at the blade roots around these areas; namely, at the inlet edges and the areas about a half pitch chord length from the inlet. Usually, the magnitude of the alternating stress is the highest at the upper and lower fillets of the inlet edge of blade.

Stress measurements of runner were conducted on the pump-turbines installed at the power stations listed in Table 2.

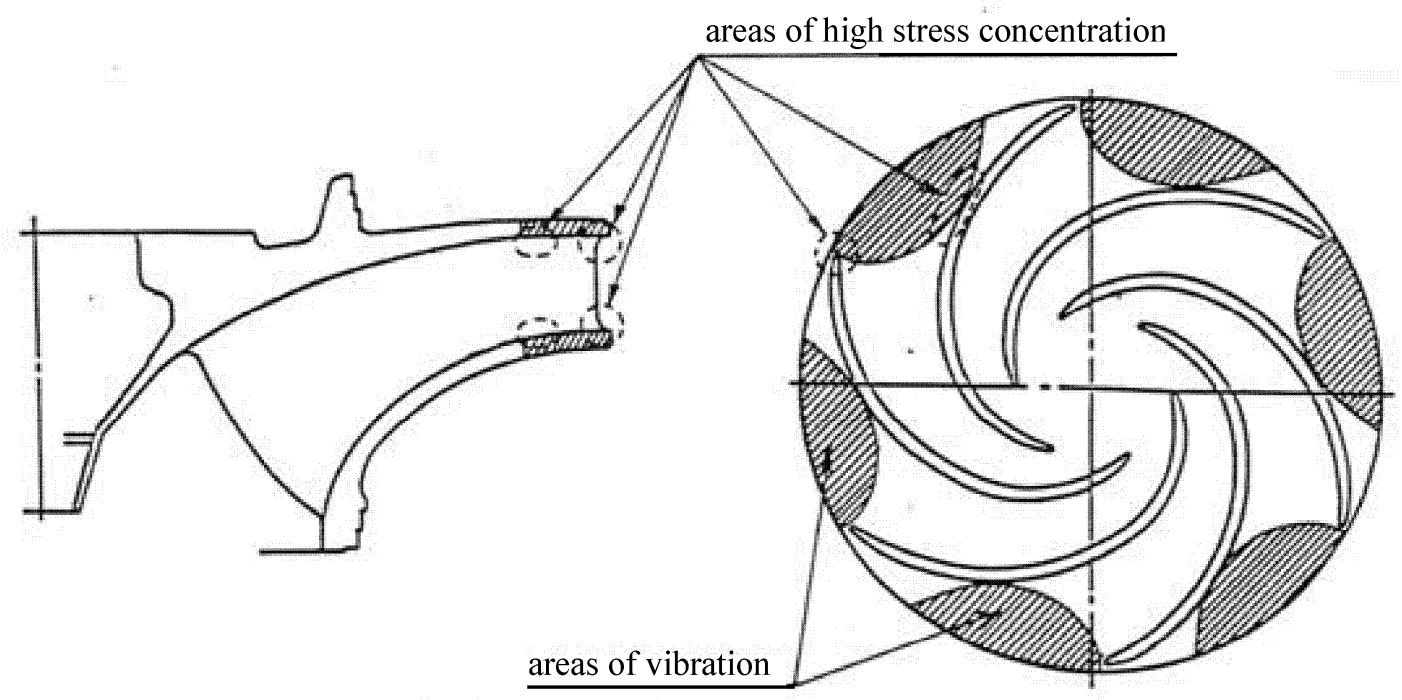

Fig. 4 Areas of the vibration excited by hydraulic forcing due to interference of blade cascades and areas of the concentration of vibration stress

Table 2 High head pump-turbines on which stress measurements of runner were conducted

\begin{tabular}{|c|c|c|c|c|c|}
\hline \multirow[b]{2}{*}{ P. S. } & \multicolumn{2}{|c|}{ as turbine } & \multicolumn{2}{|c|}{ as pump } & \multirow[b]{2}{*}{$\begin{array}{l}\text { speed } \\
\text { (rpm) }\end{array}$} \\
\hline & $\begin{array}{l}\text { head } \\
(\mathrm{m})\end{array}$ & $\begin{array}{l}\text { output } \\
\text { (MW) }\end{array}$ & $\begin{array}{l}\text { head } \\
\text { (m) }\end{array}$ & $\begin{array}{l}\text { input } \\
\text { (MW) }\end{array}$ & \\
\hline Ohira & 512.0 & 256 & 545.0 & 269 & 400 \\
\hline Okuyoshino & 526.0 & 207 & 539.0 & 214 & 514 \\
\hline Bajina Basta & 600.3 & 315 & 621.3 & 310 & 429 \\
\hline Shimogo & 415.0 & 260 & 440.0 & 280 & 375 \\
\hline Imaichi & 539.5 & 360 & 573.0 & 361 & 429 \\
\hline
\end{tabular}


Typical examples of the measured data are shown in Fig. 5. The oscillogram traces of the alternating stresses show sinusoidal wave and they become more regular at the resonant condition, as shown in Fig. 5(a). Also, it is observed that the stresses measured at both upper and lower ends of the same inlet edge of the blade show parallel periodic variation in phase.

Figure 5(b) shows variation of frequency spectra with the change of turbine output. The dominating frequency always corresponding to $\left(Z_{g} \cdot N\right) \mathrm{Hz}$ and no high order harmonics are usually observed. It means that, among the frequencies represented by Eq. (1), only the principal frequency given by $n=1$ is actually observed.

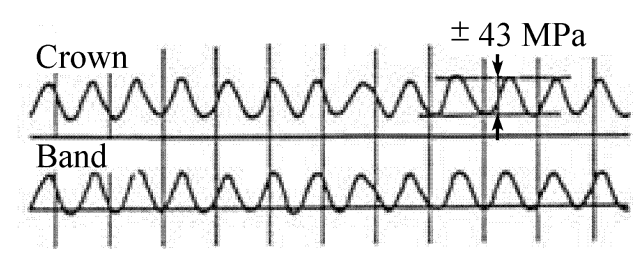

$\underline{\text { Resonant condition }(82 \% \text { speed })}$

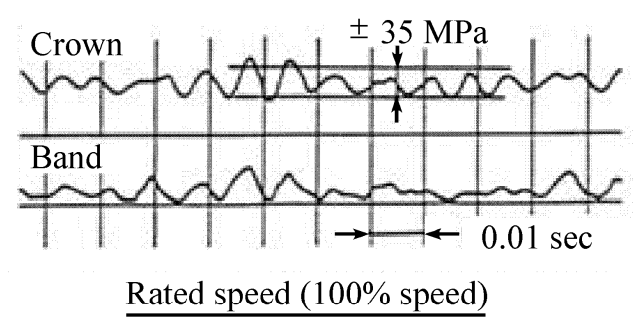

(a) Time process of dynamic stress of runner (Inlet edges of a blade, at corners on crown and on band)

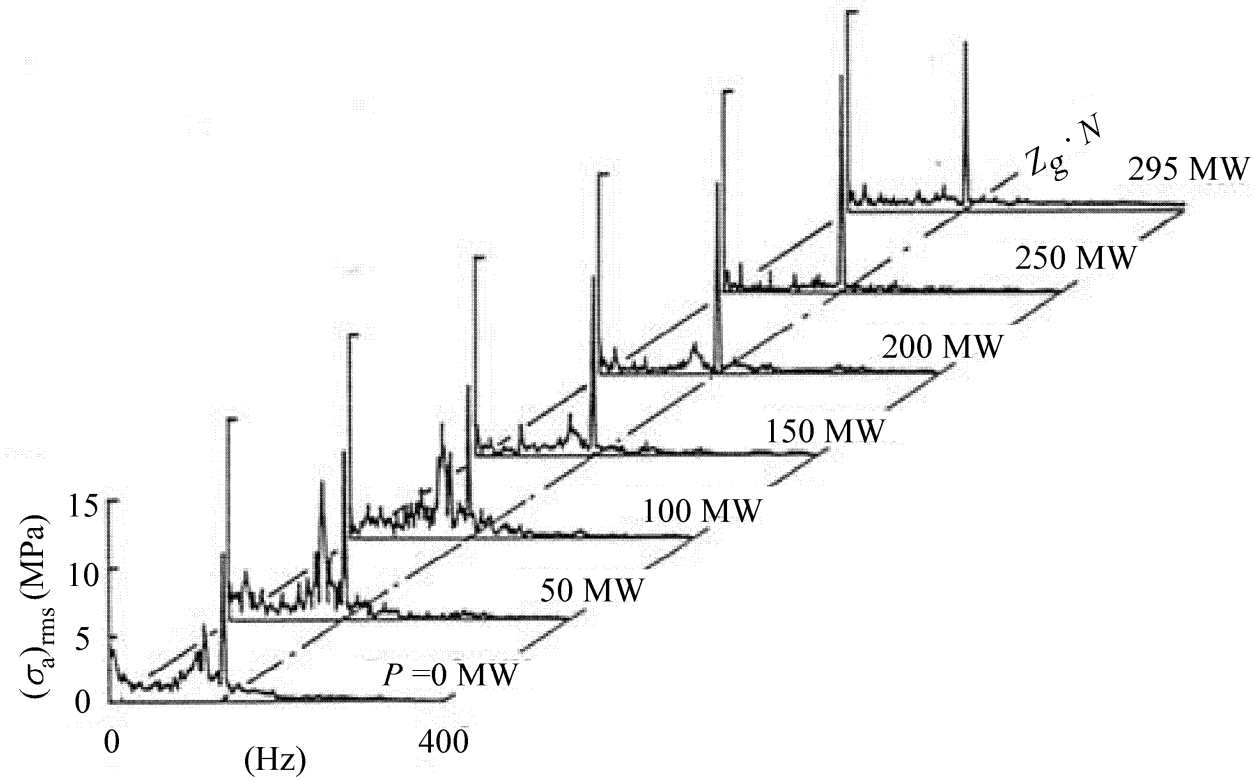

(b) Frequency spectra of the stress at the inlet edge

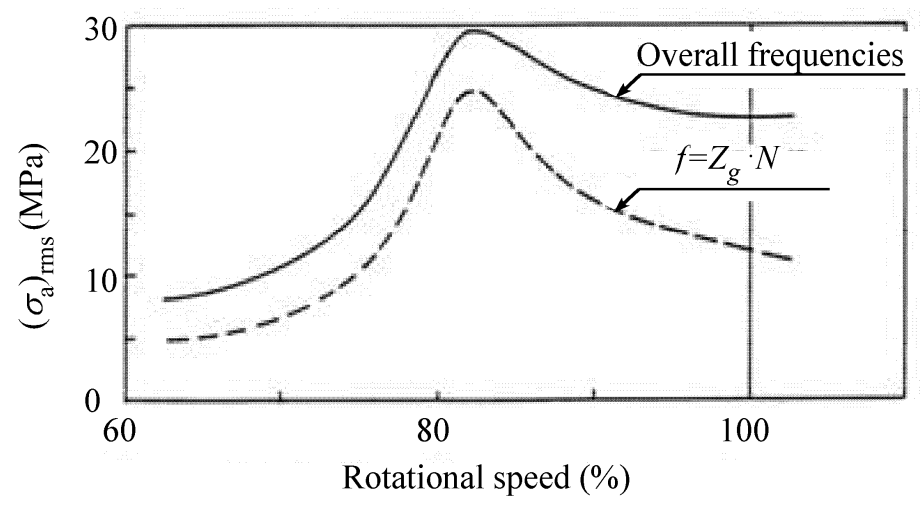

(c) Resonance characteristics of the runner

Fig. 5 Examples of the results of measurements of the vibration stress of a prototype runner

The amplitude of the alternating stress shows no significant change with the output as shown in Fig. 5(b) but it changes considerably with operating speed as shown in Fig. 5(c).

Figure 6 shows two examples of the change of amplitude of alternating stress with the operating speed. They represent resonance characteristics of these runners.

Resonance of runner A takes place at a speed close to the rated speed. Consequently, the amplitude of alternating stress of runner $A$ at the rated speed is larger than that of runner B. Also it is observed that maximum peak value of the amplitude of runner $\mathrm{A}$ is higher than that of runner $\mathrm{B}$. These differences result from higher resonant speed and lower damping of runner A. 


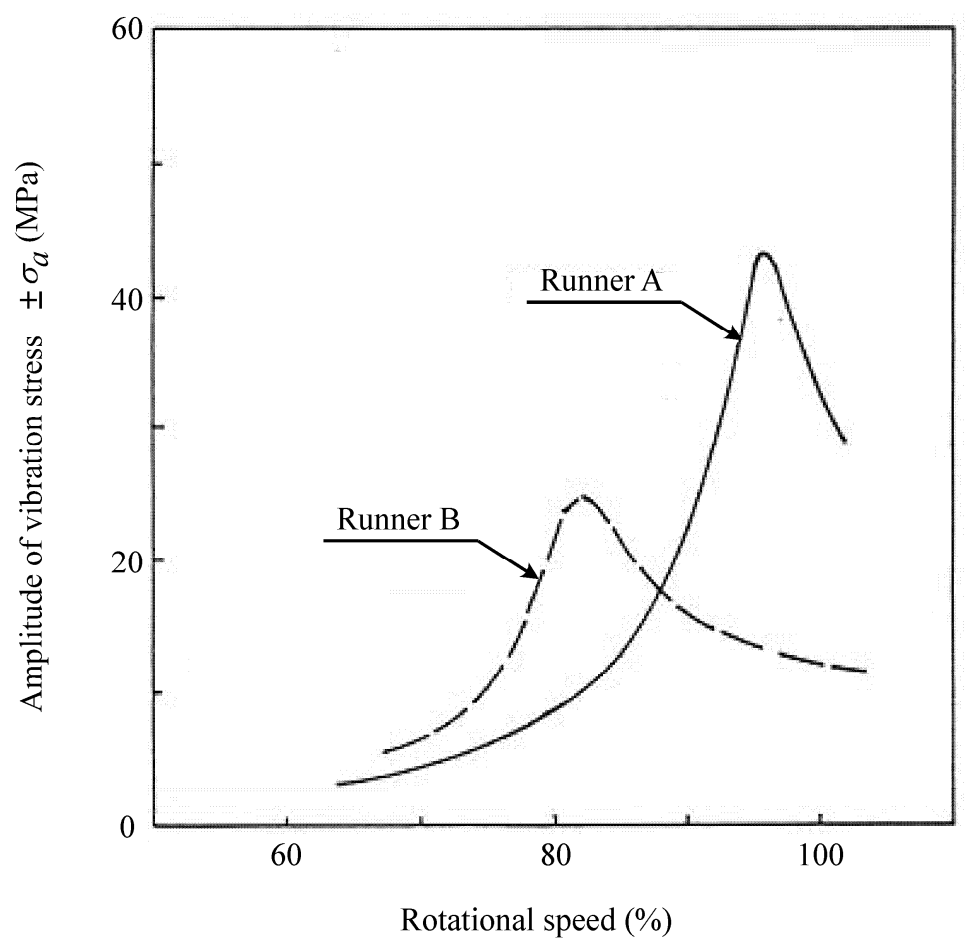

Fig. 6 Comparison of resonance curves of two different runners

Figure 7 shows examples of the frequency spectra of the vibration of a head cover and a guide vane arm. Since the unit has a 6 bladed runner and 20 guide vanes, they show two dominant frequencies, $18 \mathrm{~N}$ and $24 \mathrm{~N} \mathrm{~Hz}$. They correspond to ( $\left.3 \cdot Z_{r} \cdot N\right)$ for 2 diametrical nodes and $\left.\left(4 \cdot Z_{r} \cdot N\right)\right)$ for 4 diametrical nodes, respectively.

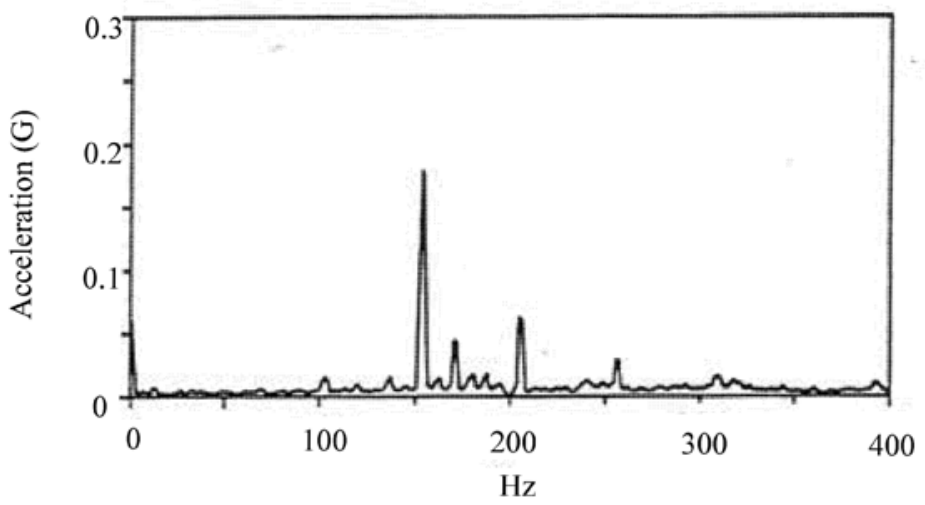

(a) Head cover (vertical)

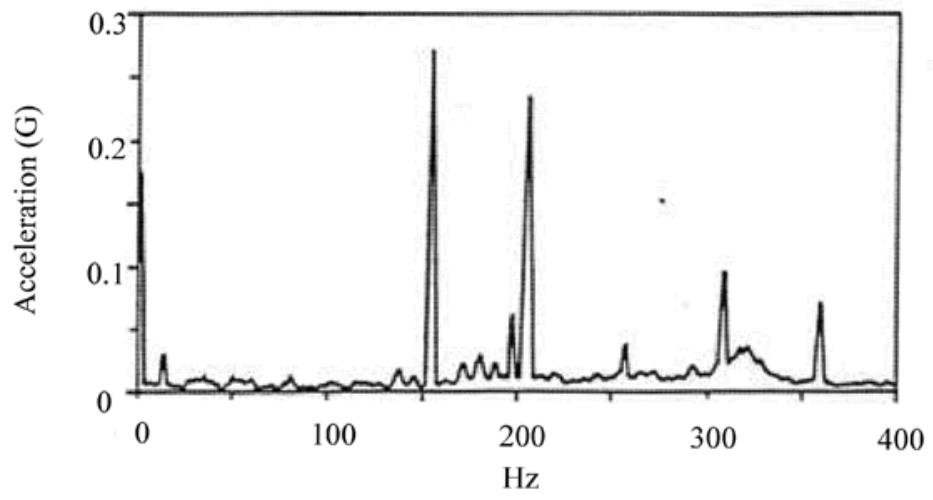

(b) Guide vane arm (horizontal)

$$
\begin{aligned}
N=514 \mathrm{rpm} & =8.57 \mathrm{~Hz} \\
3 Z_{r} \cdot N=18 N & =154 \mathrm{~Hz} \\
4 Z_{r} \cdot N=24 N & =206 \mathrm{~Hz}
\end{aligned}
$$

Fig. 7 Spectra of the vibration of head cover 


\section{Model Tests under Hydrodynamic Similarity}

For experimental studies on the vibration phenomena which involve interaction between flow and structure, model tests in accordance with hydrodynamic similarity are useful.

If a model is made accurately homologous to the prototype, the relationship between the natural frequencies of the prototype and those of the model is given by the following equation.

For a model made of different material: $f_{n}^{\prime}=\left(E^{\prime} / E\right)^{1 / 2}\left(\rho / \rho^{\prime}\right)^{1 / 2} S \cdot f_{n}$

For a model made of the same material as of the prototype: $f_{n}^{\prime}=S \cdot f_{n}$

where, $f_{n}$ : natural frequency

$E$ : Young's modulus of the material

$\rho$ : density of the material

$S$ : scale ratio of the model, $S=\left(D / D^{\prime}\right)$

$D$ : reference diameter of runner

' (prime): values for the model while those without prime are for the prototype

Since the frequencies of the hydraulic excitation $f_{h}$ are related to $(v / D)$ or the frequency of runner rotation $N$, their relationship between model and prototype is given as follows.

where, $v$ : flow velocity at a reference point

$$
f_{h}^{\prime}=\left(v^{\prime} D / v D^{\prime}\right) f_{h}=\left(N^{\prime} / N\right) f_{h}
$$

$f_{h}$ : frequency of hydraulic excitation

$N$ : frequency of runner rotation

Then, if a model is tested under the following condition, dynamic response of the model to the hydraulic excitation is similar to that of the prototype.

$$
\left(f_{n}^{\prime} / f_{h}^{\prime}\right)=\left(f_{n} / f_{h}\right)
$$

This leads to the following similarity law for the model made of the same material as of the prototype,

$$
S\left(N / N^{\prime}\right)=1
$$

or,

$$
\begin{gathered}
D \cdot N=D^{\prime} \cdot N^{\prime} \\
U=U^{\prime} \\
H=H^{\prime}
\end{gathered}
$$

Therefore, if a model runner made of the same material is tested under the same head as for the prototype, vibration phenomena induced by interaction between flow and structure can be simulated by the model test. The relationship between the

\begin{tabular}{|c|c|c|c|}
\hline Quantities & Prototype & Model & Note \\
\hline Relative dimension & 1 & $\frac{1}{S}$ & $\begin{array}{c}S: \text { scale ratio } \\
\quad=\left(D / D^{\prime}\right)\end{array}$ \\
\hline Rotating speed (rps) & $N$ & $S \cdot N$ & \\
\hline $\begin{array}{l}\text { Peripheral velocity } \\
\text { of runner }(\mathrm{m} / \mathrm{s})\end{array}$ & $U$ & $U$ & \\
\hline Net head $(\mathrm{m})$ & $H$ & $H$ & $\begin{array}{l}\text { Model test head } \\
=\text { Prototype head }\end{array}$ \\
\hline Power (kW) & $P$ & $\frac{1}{S^{2}}$ & \\
\hline Stress (MPa) & $\sigma$ & $\sigma$ & \\
\hline Frequency $(\mathrm{Hz})$ & $f$ & $S \cdot f$ & \\
\hline
\end{tabular}
quantities of the model and those of the prototype is shown in Table 3. If a model test is conducted, for example, using a 1/10 scale model of the prototype rated as $300 \mathrm{MW}$ with a speed of $600 \mathrm{rpm}$, the model requires driving power of $3000 \mathrm{KW}$ with rotational speed of $6000 \mathrm{rpm}$. Usually, to establish a resonance curve, about 1.2 times operating speed and 1.7 times power are required for the test; namely, about $7000 \mathrm{rpm}$ and $5000 \mathrm{KW}$, respectively, for this example.

Table 3 Similarity between a prototype and a model tested under the prototype head 
An example of the test rig for such test is shown on Fig. 8. It uses a power compensating pump-turbine to reduce the power required.
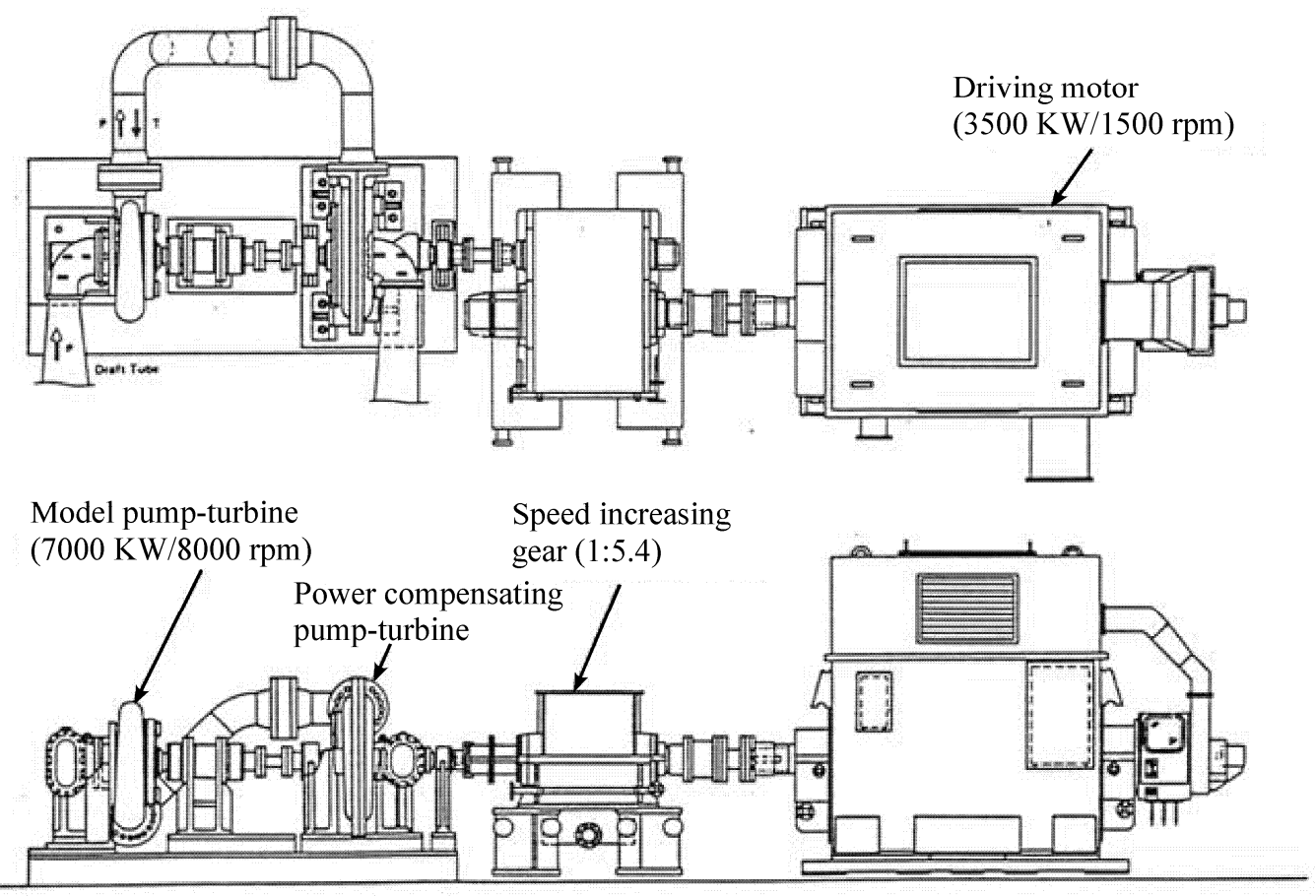

Fig. 8 Test rig for prototype head model tests

Figure 9 shows some examples of the test results obtained by a prototype head model test. Figure 9(a) shows an oscillogram trace of the stress of the model runner. It gives similar aspect to that of the prototype as shown on Fig. 5(a).

Figure 9(b) shows the trend diagrams of frequency spectra with the change of test speed. Similar to those for the prototype, it shows a dominant frequency corresponding to $Z_{g} \cdot N \mathrm{~Hz}$.

Figure 9(c) is a resonance curve obtained by model test.

By comparing the natural frequency of the model runner in air with the resonance frequency of the runner obtained by the prototype head model test, the reduction ratio of the natural frequency in water is computed and the added mass effect can be assessed.

\section{Natural Frequency of Runner}

\subsection{Normal modes of runner}

Figure 10 shows an example of the normal modes of a 6 blade runner measured in air. These modes are divided into two groups. One group is for the modes of which the displacements of runner crown and band are mostly in-phase and the other is for those with their displacements counter-phase.

In-phase modes, which are denoted by I.P., usually show fairly neat sinusoidal displacement curves along the runner periphery. On the other hand, counter-phase modes, which are denoted by C.P., show complex displacement curve. In case of in-phase modes, both crown and band deflects in parallel, while, in case of counter-phase modes, they deflect in opposite direction. Therefore, counter-phase modes essentially require elastic elongation and contraction of blades to allow the relatively opposite displacements of crown and band. However, the structural restraint by blades is so strong that counter-phase modes must take mode shapes such as relative displacement between crown and band is very small at each blade position. This makes the mode shapes of counter-phase modes complex.

Since the hydraulic excitation force (pressure fluctuation) is imposed in phase on the surfaces of runner crown and band facing to main water passage, it induces primarily counter-phase modes of runner vibration. In effect, the stresses measured at the upper and lower root fillets of an inlet edge of blade show parallel variations in most cases. This indicates the runner crown and band vibrate with a counter-phase mode.

It has been known that, in case of $Z_{g}=20$ and $Z_{r}=6$, the mode primarily induced is No. 6 shown in Fig. 10, which has two large displacement peaks along the runner periphery and is classified as a counter-phase 2 diametrical node mode.

Further studies on the counter-phase modes have revealed that such modes could be expressed as the combinations of two imaginary elementary modes.

According to the theory stated in paragraph 2, the principal vibration modes in case of $Z_{g}=20$ and $Z_{g}=6$ are the one with 2 diametrical nodes, spinning to reverse direction with the spinning frequency of $10 \mathrm{~N}$, and the one with 4 diametrical nodes, spinning to forward direction with the frequency of $5 \mathrm{~N}$. It was found recently that the superposition of these two modes produced a mode which had 6 radial nodes (or 3 diametrical nodes) around the periphery. 


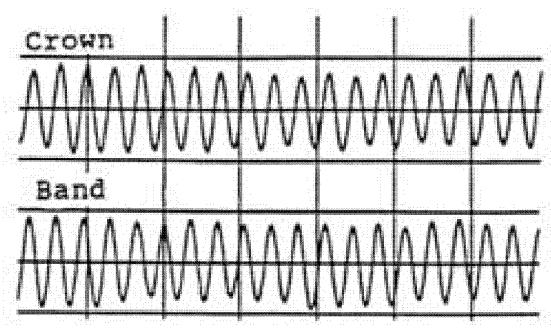

$\underline{\text { Resonant condition (4300rpm) }}$

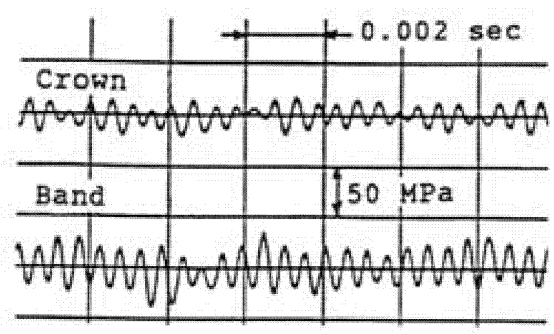

$\underline{\text { Rated condition (5700rpm) }}$

(a) Time process of dynamic stress of runner (Inlet edges of a blade, at corners on crown and on band)

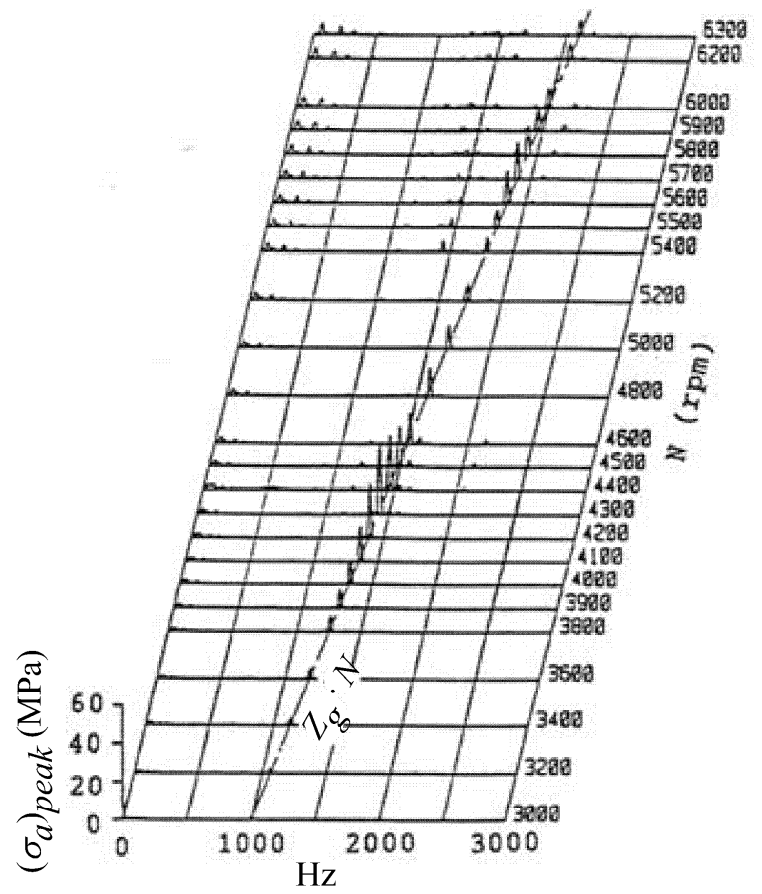

(b) Frequency spectra of the stress at the inlet edge

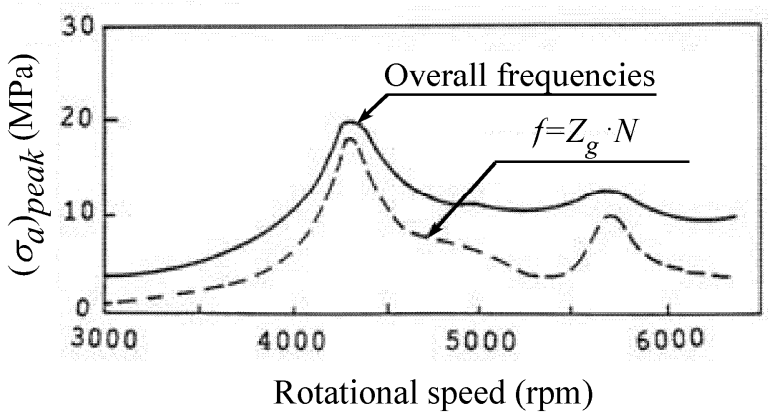

(c) Resonance characteristics of the runner

Fig. 9 Examples of test results of a prototype head model test

Figure 11(a) shows the mode shape of runner crown or band which are extended for $\phi=0$ to $2 \pi$ corresponding to the runner periphery and arranged vertically to show their time dependent variation. Those at the left and the middle represent elementary modes corresponding to $k=+4$ and -2 , and the right shows the combined mode obtained by their superposition.

Figure 11(b) shows time process of 11 points distributed along the runner periphery over two blade pitches. In elementary modes, all points moves similarly but, in the combined mode, stationary points appear at every blade pitch.

In Fig. 11(c), two of the above combined modes are arranged in counter-phase to represent the mode shape of both crown and band. It shows very similar aspect to the one observed on the actual runner as shown in Fig. 11(d). In other words, the actual mode observed in runner vibration is a combination of two simple elementary modes.

As recognized in Fig. 11, if each of these elementary modes takes the form of a counter-phase mode, it requires elastic deformation of blades. Therefore, they can not exist individually. But, if they take place together, the combined mode has a node at each blade position and it can exist realistically satisfying the structural boundary condition. 


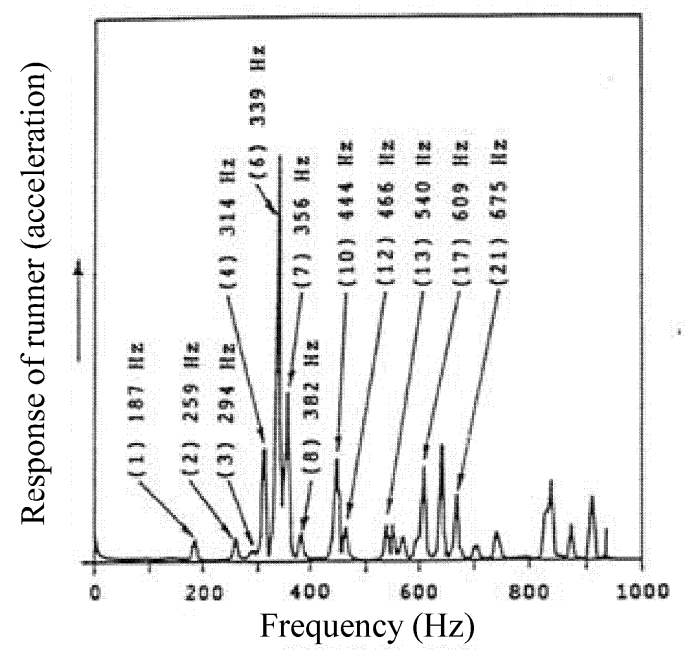

(a) Frequency response of a prototype runner $(\mathrm{D}=3,760 \mathrm{~mm})$

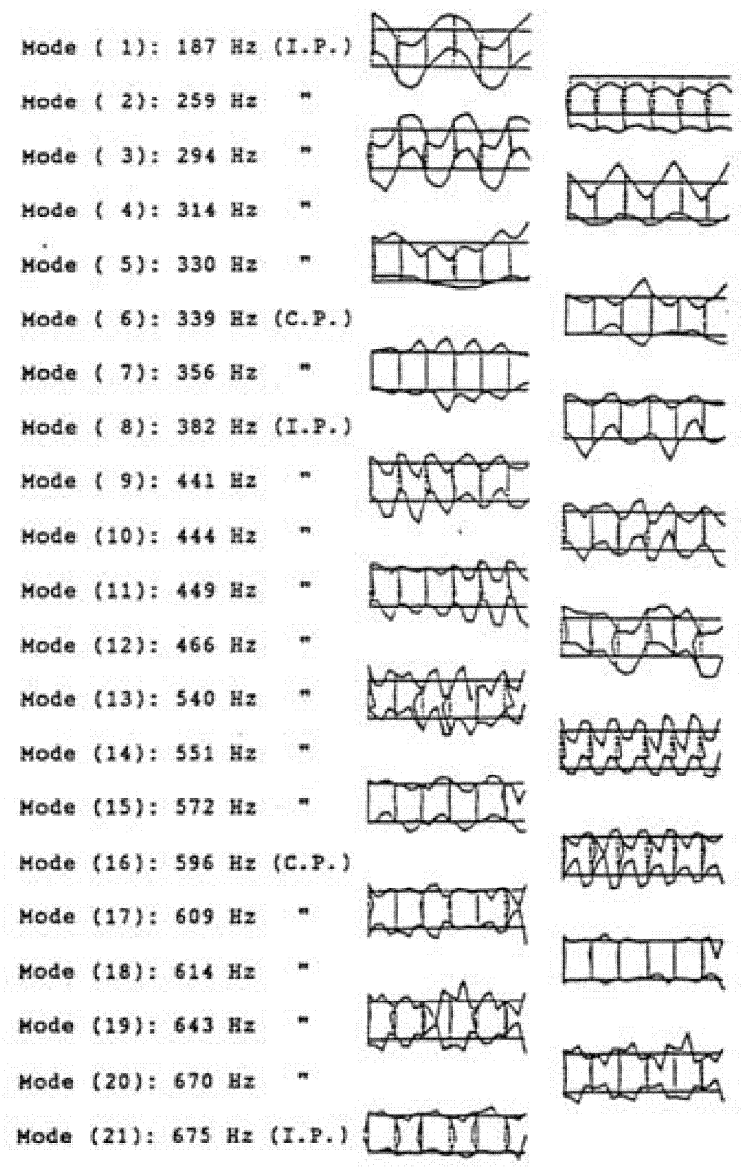

(b) Normal modes of the runner

Fig. 10 Examples of normal models of a runner $\left(Z_{r}=6\right.$; measured in air)
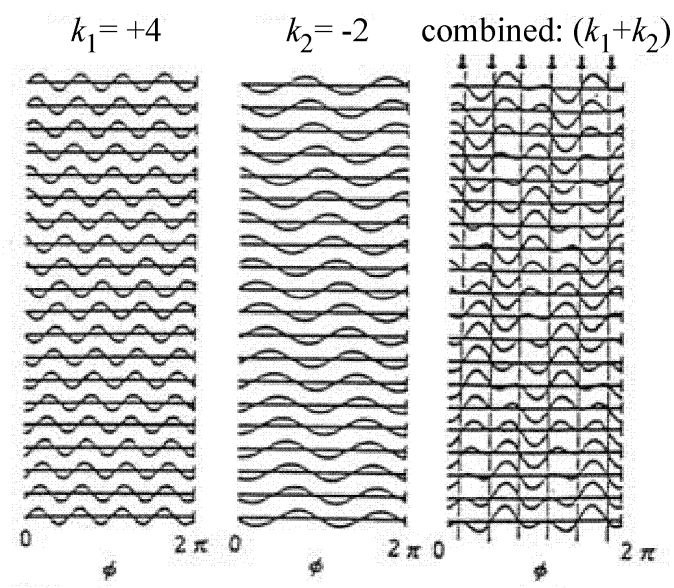

(a) Mode pattern along runner periphery

$$
k_{1}=+4 \quad k_{2}=-2 \quad \text { combined: }\left(k_{1}+k_{2}\right)
$$

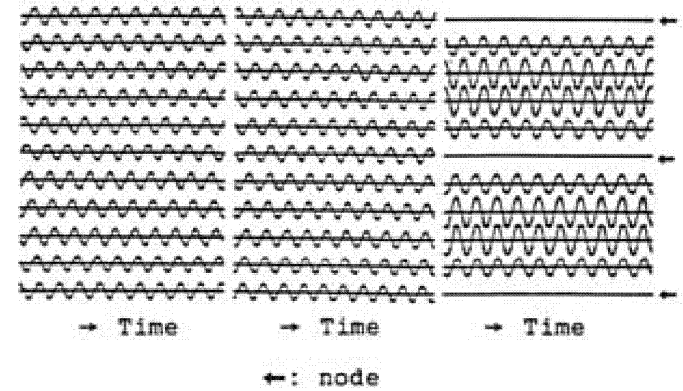

(b) Time history of the motion of points on runner periphery

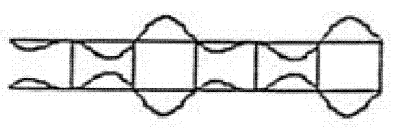

(c) Mode pattern of runner crown and band vibration in the combined mode $\left(k_{1}+k_{2}\right)$ with counter phase

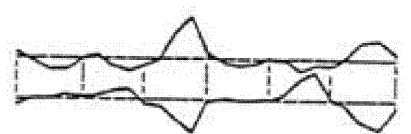

(d) Mode pattern of the vibration actually excited on a prototype runner

Fig. 11 Combined mode of 2- and 4- diametrical node modes 
If this combined mode is observed from the stationary coordinates, the two elementary modes are recognized separately as a 2 diametrical node mode with the frequency of $3 \cdot Z_{r} \cdot N$ and a 4 diametrical node mode with the frequency of $4 \cdot Z_{r} \cdot N$.

Such a counter-phase mode taking the form of combination of two elementary modes and having the same number of radial nodes as of the blades can be always constituted for any combination of $Z_{g}$ and $Z_{r}$.

It is proved as follows; [2]

$$
\begin{aligned}
& X_{1}=A_{0} \sin \left(2 \pi \cdot f_{r} \cdot t-k_{1} \cdot \phi\right) \\
& X_{2}=A_{0} \sin \left(2 \pi \cdot f_{r} \cdot t+k_{2} \cdot \phi\right)
\end{aligned}
$$

where, $X_{1}$ : one vibration mode having $k_{1}$ diametrical nodes with progressive wave form

$X_{2}$ : the other vibration mode having $k_{2}$ diametrical nodes with retrogressive wave form

$k_{1}$ : number of diametrical nodes of the first mode

$k_{2}$ : number of diametrical nodes of the second mode

Then,

$$
X_{1}+X_{2}=2 A_{0} \cos \left[\left(k_{1}+k_{2}\right) \phi / 2\right] \sin \left[2 \pi \cdot f_{r} \cdot t-\left(k_{1}-k_{2}\right) \phi / 2\right]
$$

If the combination of two smallest values of $k$ is selected for $k_{1}$ and $k_{2}$, the sum $\left(k_{1}+k_{2}\right)$ is equal to $Z_{r}$ according to Eq. (13). Therefore, the cosine function in the amplitude term of Eq. (24) becomes zero at $Z_{r}$ locations in the range of $\phi$ from 0 to $2 \pi$. That means the combined mode $\left(X_{1}+X_{2}\right)$ has $Z_{r}$ radial nodes.

Therefore, in general, when a runner vibrates forced by the excitation due to hydraulic interference between runner blades and guide vanes, it takes primarily this combined mode; that is a counter-phase mode having nodes at the blade positions.

Sometimes an in-phase mode is recognized when a model is tested. This is excited by uneven pressure fluctuation on runner crown and on band and it usually appears in lesser degree at a higher rotational speed under higher operating head.

\subsection{Natural frequency of runner in water}

In general, natural frequency of a structure is reduced in water due to the added mass effect of water. When a structure is submerged in open water, the reduction ration of the natural frequency in water from that in air, which is denoted by a hereinafter, is somewhere around 0.8. However, like a runner installed in machine, if it is confined in a narrow space, the water around the runner must move with much larger amplitude than the runner itself and it causes very high added mass effect.
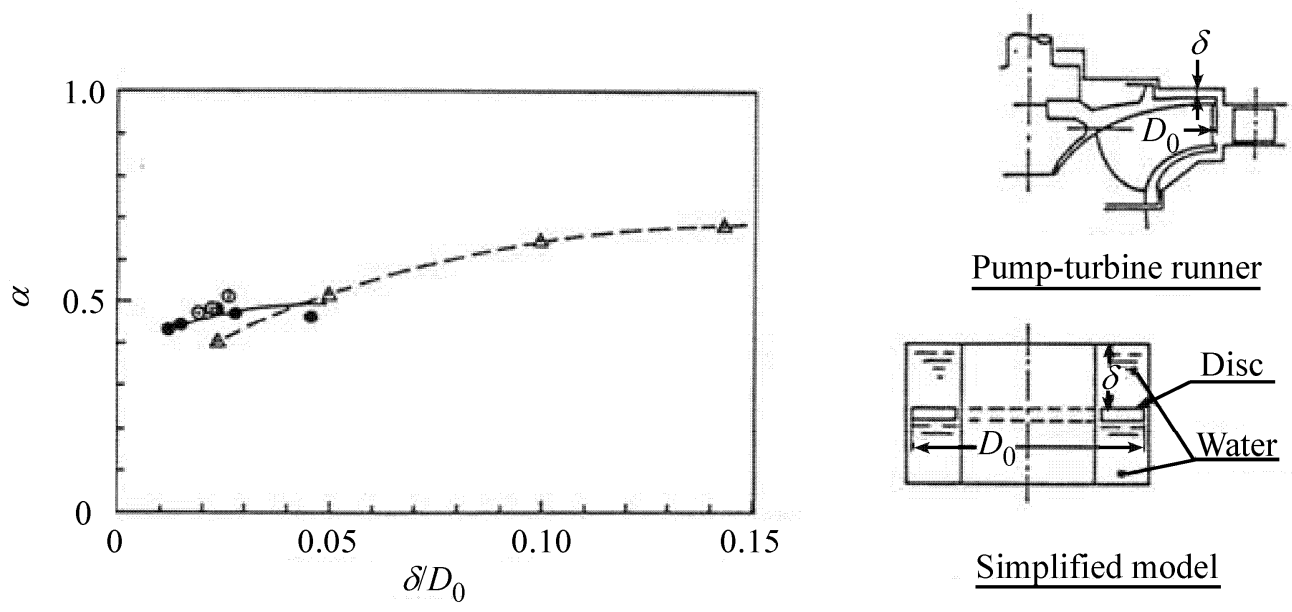

$\underline{\text { Pump-turbine runner }}$

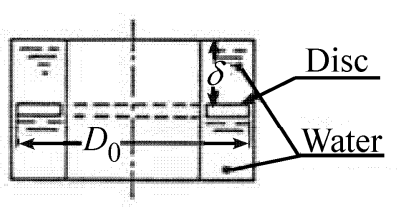

$\underline{\text { Simplified model }}$

- Prototype

- Model pump-turbine (prototype head test)

$\Delta$ Simplified model

Fig. 12 Reduction ratio of natural frequency in water, $\alpha$, for 2 diametrical node mode

Figure 12 shows the experimental results of the natural frequency reduction ratio for 2 diametrical node mode, which is prevalently observed on the machine with $Z_{g}=20$ or 16 and $Z_{r}=6$. Both the results measured on the prototypes and on the models give similar values in the range of 0.45 to 0.50 , much less than those observed in open water.

The reduction ratio is influenced significantly by vibration mode and the space around the runner. Figure 13 shows the value of a when a single circular disc is confined in a cylindrical vessel with water.[3] It is given as a function of the number of diametrical nodes of the vibration mode and of the distance between the disc and the stationary wall. For the less number of diametrical nodes, it takes very low values since the amplitude of the surrounding water becomes larger. The theoretical values in Fig. 13 were obtained y potential flow analysis on the assumption that no radial flow was present. 


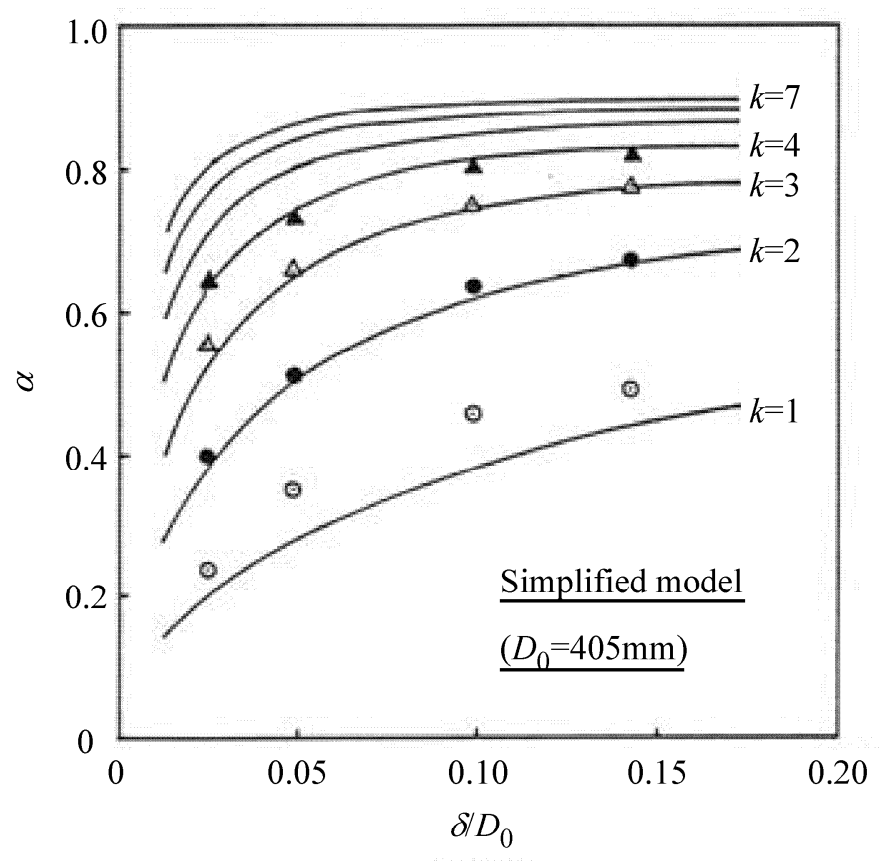

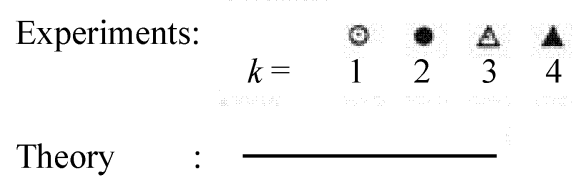

Fig. 13 Reduction ratio of natural frequency in water, $\alpha$, for multiple diametrical node modes

Besides the above, the value of the frequency reduction ratio is also influenced by the design profile of the runner. Figure 14 shows one example. When the outer peripheries of the runner crown and band are tapered off, the natural frequency of the runner in air does not change significantly since the reduction of both mass and stiffness is nearly the same degree. However, the natural frequency in water decreases significantly by this modification. This is interpreted as the mass effect of the runner in water is mostly attributed to the added mass effect of the water rather than the mass of the runner itself and the modification contributes only to the reduction of the stiffness but not significantly to the reduction of the total mass.

Consequently, in this example, the frequency reduction ratio in water for the modified runner is less than the original one.
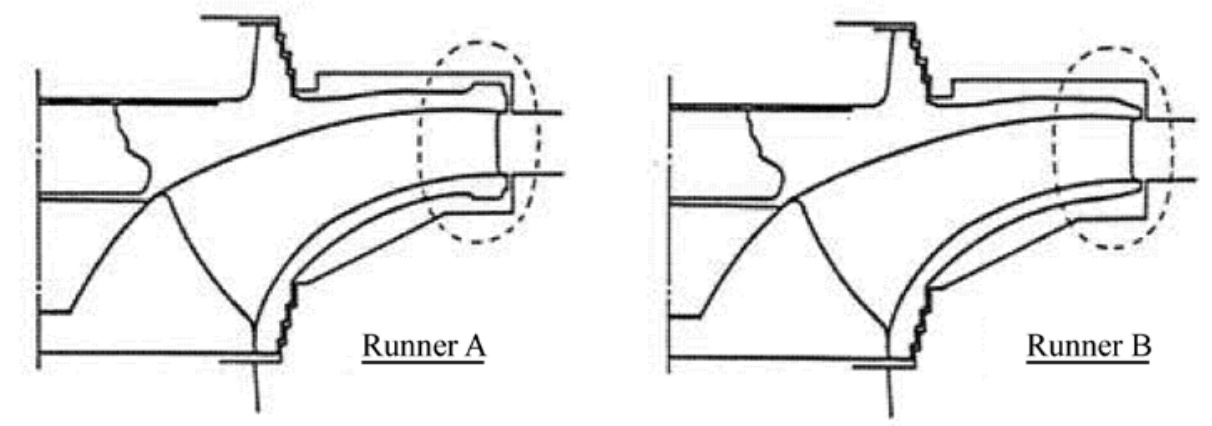

\begin{tabular}{|c|c|c|c|}
\hline & $\begin{array}{c}\text { Natural frequency } \\
\text { in air } \\
f_{n a}(\mathrm{~Hz})\end{array}$ & $\begin{array}{c}\text { Natural frequency } \\
\text { in water } \\
f_{n w}(\mathrm{~Hz})\end{array}$ & $\begin{array}{c}\text { Reduction ratio } \\
\text { of frequency in } \\
\text { water, } \alpha=f_{n w} / f_{n a}\end{array}$ \\
\hline Runner A & 3003 & 1433 & 0.48 \\
\hline Runner B & 2950 & 1300 & 0.44 \\
\hline
\end{tabular}

Fig. 14 Influence of runner design profile on the reduction ratio of natural frequency in water

\section{Influential Factors on the Vibration of the Runner}

\subsection{Combination of $Z_{r}$ and $Z_{g}$}

Figure 15 shows the curves of the dynamic response of runners obtained by the prototype head model tests for various combinations of $Z_{r}$ and $Z_{g}$. The models tested were of the similar design having the same specific speed.

It is evident by these curves that the magnitude of the response depends significantly on the combination of $Z_{r}$ and $Z_{g}$. 


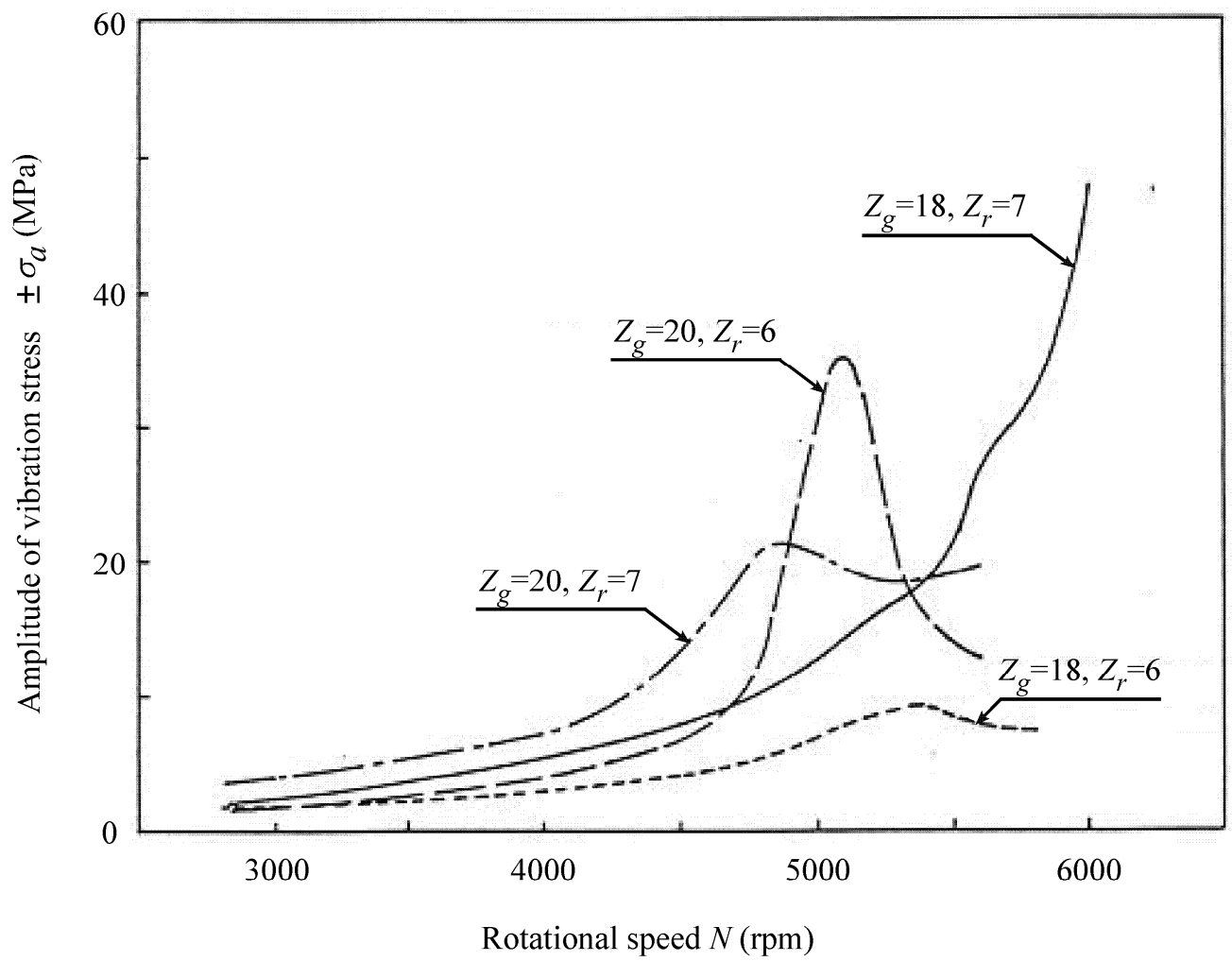

Fig. 15 Experimental results of the resonance curves for different combinations of $Z_{g}$ and $Z_{r}$

Since the design of guide vanes and the blade angle of the runner are similar for these tests, the magnitude of individual impact of the hydraulic excitation due to the interference of blade cascades is almost identical.

In addition, the design of head cover and the values of runner seal clearances for these models are similar.

Therefore, the difference of the response of these models are attributable to the difference of the vibration mode due to the different combinations of $Z_{g}$ and $Z_{r}$.

It has been made clear that such difference of the vibration mode caused the difference in the phase lag between the excitation forces imposed on two adjoining runner blades and it results different magnitude of response. [4]

As shown in Fig. 16, the crown and the band between two blades deflect by larger displacement, if the forces on two adjoining blades are applied with $180^{\circ}$ phase lag. In other words, the larger the phase difference between the forces on two adjoining blades, the larger the deflection of the runner.

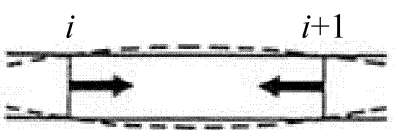

(a) $F_{i+1}=-F_{i}$ (phase lag: $180^{\circ}$ )

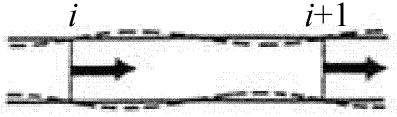

(b) $F_{i+1}=F_{i} \quad\left(\right.$ phase lag: $\left.0^{\circ}\right)$

Fig. 16 Deflections of runner crown and band when hydraulic impacts are applied to two adjoining blades in different phases

If it is assumed that the hydraulic excitation force varies sinusoidally, the force imposed by $Z_{g}$ guide vanes on one particular $i$ th runner blade is represented as follows;

$$
F_{i}=F_{0} \sin \left(Z_{g} \cdot \theta\right)
$$

where, $\theta$ is angular coordinate on the stationary coordinates and given by,

$$
\theta=\left[2 \pi \cdot N \cdot t+2 \pi(i-1) / Z_{r}\right]
$$

Therefore, the difference of the impact between two adjoining blades $|\Delta F|$ is given by the following equation.

$$
\begin{aligned}
|\Delta F| & =\left|F_{i+1}-F_{i}\right|=F_{0}\left|\sin Z_{g}\left[2 \pi \cdot N \cdot t+2 \pi i / Z_{r}\right]-\sin Z_{g}\left[2 \pi \cdot N \cdot t+2 \pi(i-1) / Z_{r}\right]\right| \\
& =2 F_{0}\left|\sin \left[\left(Z_{g} / Z_{r}\right) \pi\right]\right| \cdot\left|\cos Z_{g}\left[2 \pi \cdot N \cdot t+\pi(2 i-1) / Z_{r}\right]\right|
\end{aligned}
$$

In Eq. (27), the amplitude term includes $\left|\sin \left[\left(Z_{g} / Z_{r}\right) \pi\right]\right|$, which changes for various combinations of $Z_{g}$ and $Z_{r}$ as shown in Table 4. 
Table 4 The values of $\left|\sin \left[\left(Z_{g} / Z_{r}\right) \pi\right]\right|$ for various combinations of $Z_{g}$ and $Z_{r}$

\begin{tabular}{|c|c|l|l|l|l|l|l|}
\hline \multicolumn{2}{|c|}{} & \multicolumn{7}{c|}{$Z_{g}$} \\
\cline { 2 - 8 } \multicolumn{2}{c|}{} & 14 & 16 & 18 & 20 & 22 & 24 \\
\hline \multirow{3}{*}{$Z_{r}$} & 4 & 1.00 & 0 & 1.00 & 0 & 1.00 & 0 \\
\cline { 2 - 8 } & 5 & 0.59 & 0.59 & 0.95 & 0 & 0.95 & 0.59 \\
\cline { 2 - 8 } & 6 & 0.87 & 0.87 & 0 & 0.87 & 0.87 & 0 \\
\cline { 2 - 8 } & 7 & 0 & 0.78 & 0.97 & 0.43 & 0.43 & 0.97 \\
\cline { 2 - 8 } & 8 & 0.71 & 0 & 0.71 & 1.00 & 0.71 & 0 \\
\cline { 2 - 8 } & 9 & 0.98 & 0.64 & 0 & 0.64 & 0.98 & 0.87 \\
\cline { 2 - 8 } & 10 & 0.95 & 0.95 & 0.59 & 0 & 0.59 & 0.95 \\
\hline
\end{tabular}

Hence, it is known that the response of the runner for the combinations of $\left(Z_{g}=m \cdot Z_{r}\right)$ is the smallest. But, according to Eq. (13), it is anticipated that such combinations may generate large vibration or noise due to pressure pulsation of zero diametrical node mode, though the dynamic response of the runner is the smallest. Therefore, to minimize the response of the runner, it is recommendable to adopt the combinations given by $\left(Z_{g}=m \cdot Z_{r} \pm 1\right)$ or the closest to them.

The worst combinations are those given by $\left[Z_{g}=Z_{r}(2 m+1) / 2\right]$ or the closest to them.

The test results shown in Fig. 15 substantiate the above presumption.

\subsection{Axial distance between head cover and runner}

Figure 17 shows an example of the model test results, which shows the influence of the axial distance, $\delta$, between head cover and runner, where $D_{0}$ is the diameter of runner.

It is known from this diagram that the influence on the first resonant frequency is different from that on the second resonant frequency. Such difference is supposedly caused by the relative phase difference between head cover and runner vibration at each resonant frequency.

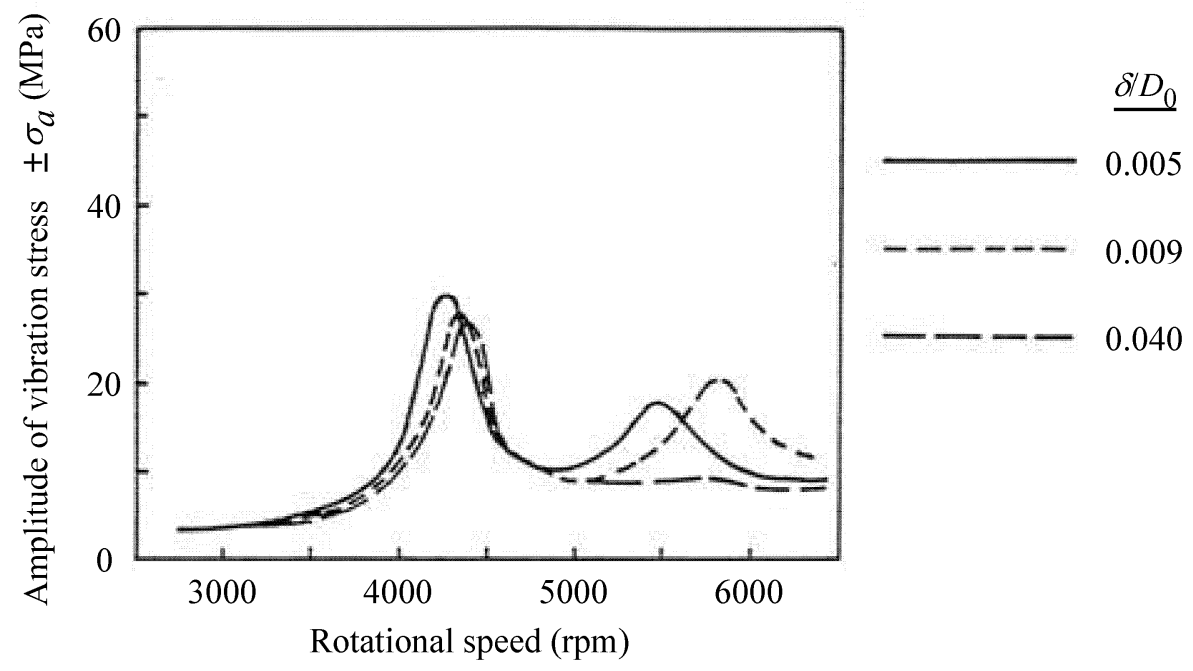

Fig. 17 Influence of the axial distance between head cover and runner on the resonance characteristics of runner

\subsection{Runner seal clearance}

When a runner vibrates, the water above and below the runner moves mostly to circumferential direction and partially toward radial direction. Though the circumferential flow does not yield significant energy loss, the radial flow causes considerable energy dissipation when passing through runner seal clearances.

Therefore, smaller runner seal clearances diminish the dynamic response of the runner as shown in Fig. 18.

Smaller clearances also make the resonance frequency lower. This is presumably caused by an increase of added mass effect due to restriction of radial flow and increase of circumferential flow.

\subsection{Radial distance between guide vanes and runner blades}

Velocity loss in the wake of guide vane causes the fluctuation of the relative inflow velocity vector to a runner blade and it gives the hydraulic excitation to the runner blade. When guide vanes are arranged closer to runner blades, recovery of the wake velocity loss is insufficient and the fluctuation of the relative inflow velocity becomes larger.

Figure 19 shows experimental results of the distribution of relative inflow velocity measured at the radius of the runner inlet. In the experiment, air flow through the guide vane cascade was traversed along the circumference of the runner inlet by a three hole Pitot probe and the absolute flow velocity was measured. Then, the relative flow velocity was calculated by subtracting the circumferential velocity vector of the runner from it. 


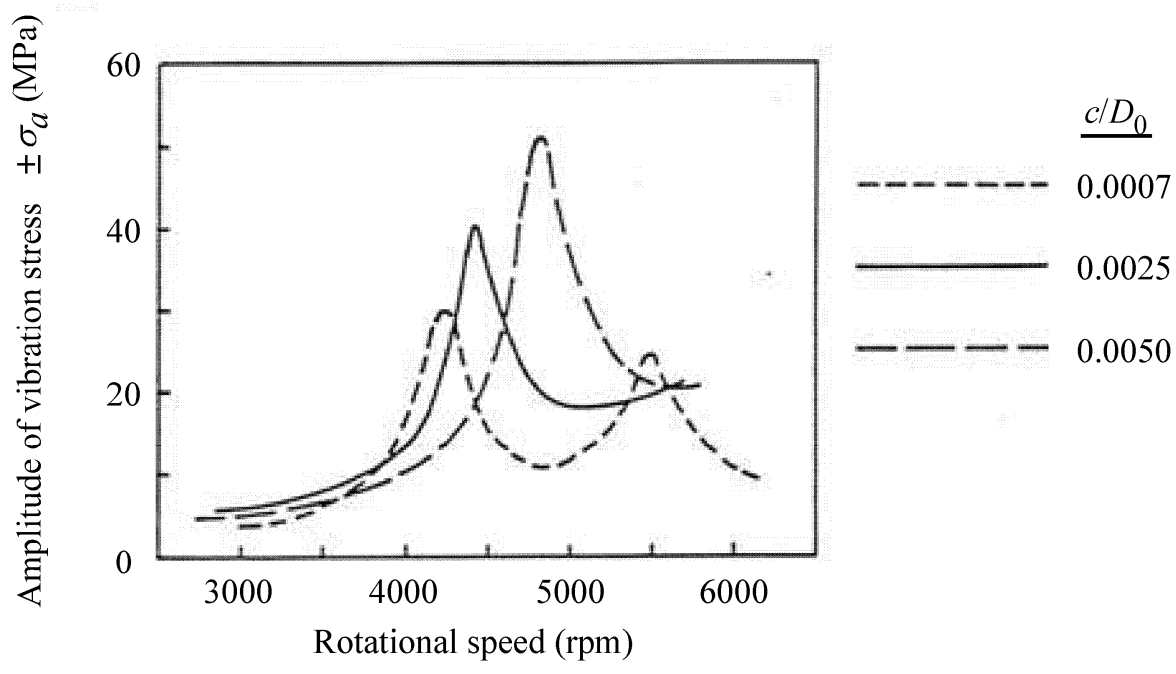

Fig. 18 Influence of the runner seal clearances on the resonance characteristics of runner

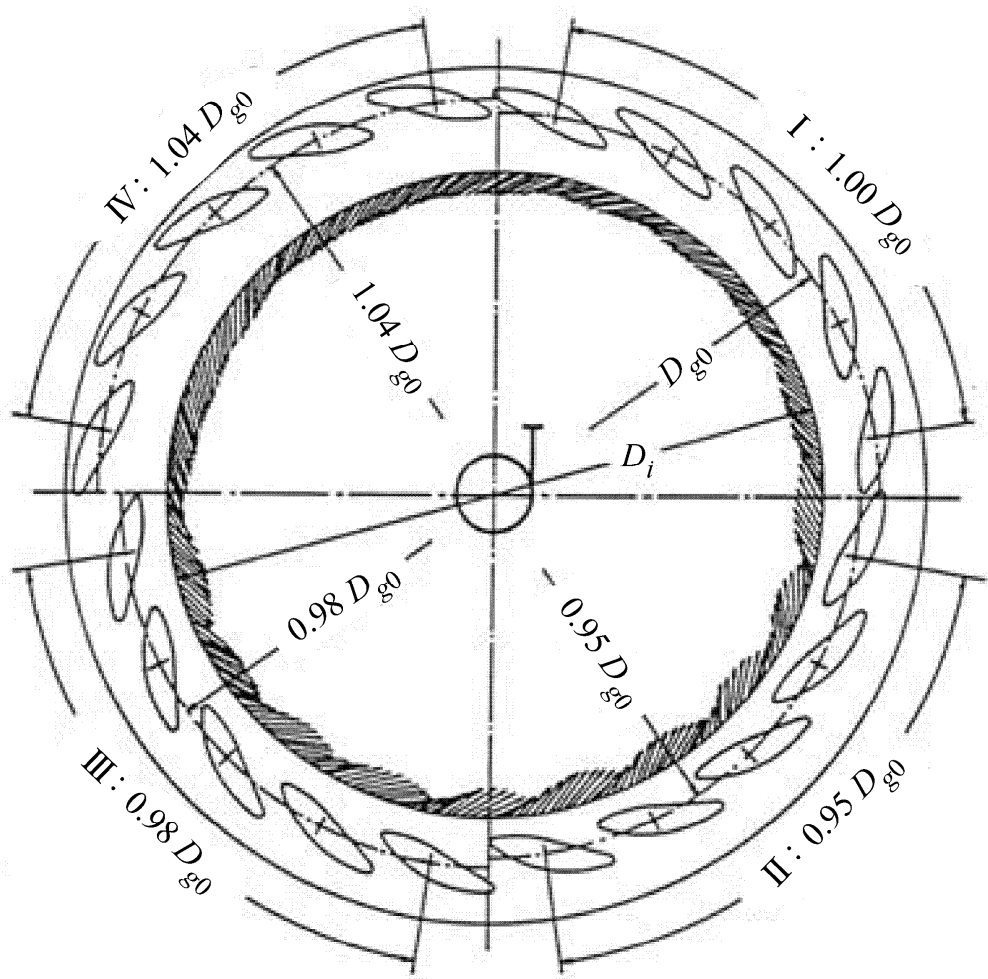

$D_{g 0}$ : guide vane pitch circle diameter of normal design

$D_{i}$ : inlet diameter of runner blades

Fig. 19 Fluctuations of relative inflow velocity due to guide vane wakes (Influence of the guide vane pitch circle diameter)

The guide vanes of this model are arranged at a different radius in each quadrant. From this figure, it is observed that the arrangement of guide vanes closer to the runner accompanies much larger fluctuation of the relative velocity vector.

Similar experiments were conducted for guide vanes with different thickness of trailing edges. The results showed that thicker trailing edges produce larger fluctuation of the relative inflow velocity.

\subsection{Design profile of runner}

External design shape of runner also gives some influence on the natural frequency of the runner as shown in Fig. 14. It should be noted that the change of natural frequency caused by the change of runner shape takes place differently in air and in water. Sometimes a design changes to increase the natural frequency in air may result in decrease of that in water like the example shown in Fig. 14. 


\section{Vibration Observed on Stationary Parts}

On the stationary parts, vibration having the modes and the frequencies as predicted by Eqs. (13), (15) and (16) is usually observed. Although these equations give numerous modes as shown in Table 1, only the vibration modes having less number of diametrical nodes are actually observed.

This is interpreted as the natural frequencies of the structure corresponding to the modes having a large number of nodes are generally very high and the structure does not respond to such hydraulic excitation.

Figure 20 shows examples of frequency spectra of pressure fluctuation and vibration measured at various parts of the pumpturbine. The pressure fluctuation measured between runner and guide vanes indicates the highest peak of the fundamental harmonics of $Z_{g} \cdot N \mathrm{~Hz}$ and its higher harmonics with reduced intensity. However, the pressure measured in the runner back chamber indicates that two frequencies corresponding to $3 \cdot Z_{g} \cdot N$ and $4 \cdot Z_{g} \cdot N$ are larger, which correspond to 2 and 4 diametrical node modes, respectively.

While these two vibration modes are remarkable, the other harmonics almost fade out. This indicates that the head cover does not respond to the hydraulic excitation such as 8 diametrical node mode, in spite of its low frequency corresponding to $\left(2 \cdot Z_{g} \cdot N\right)$ $\mathrm{Hz}$.

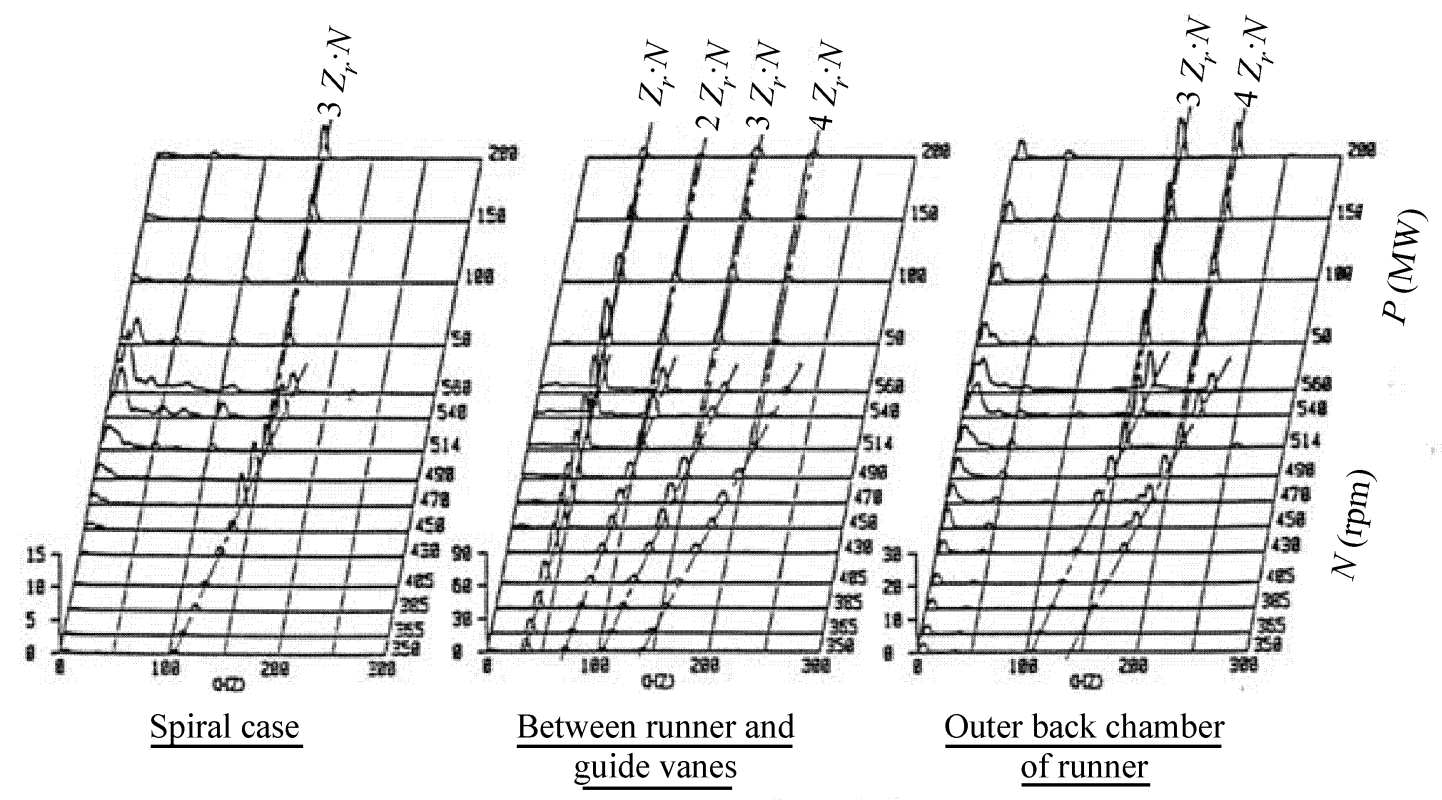

(a) Pressure fluctuation

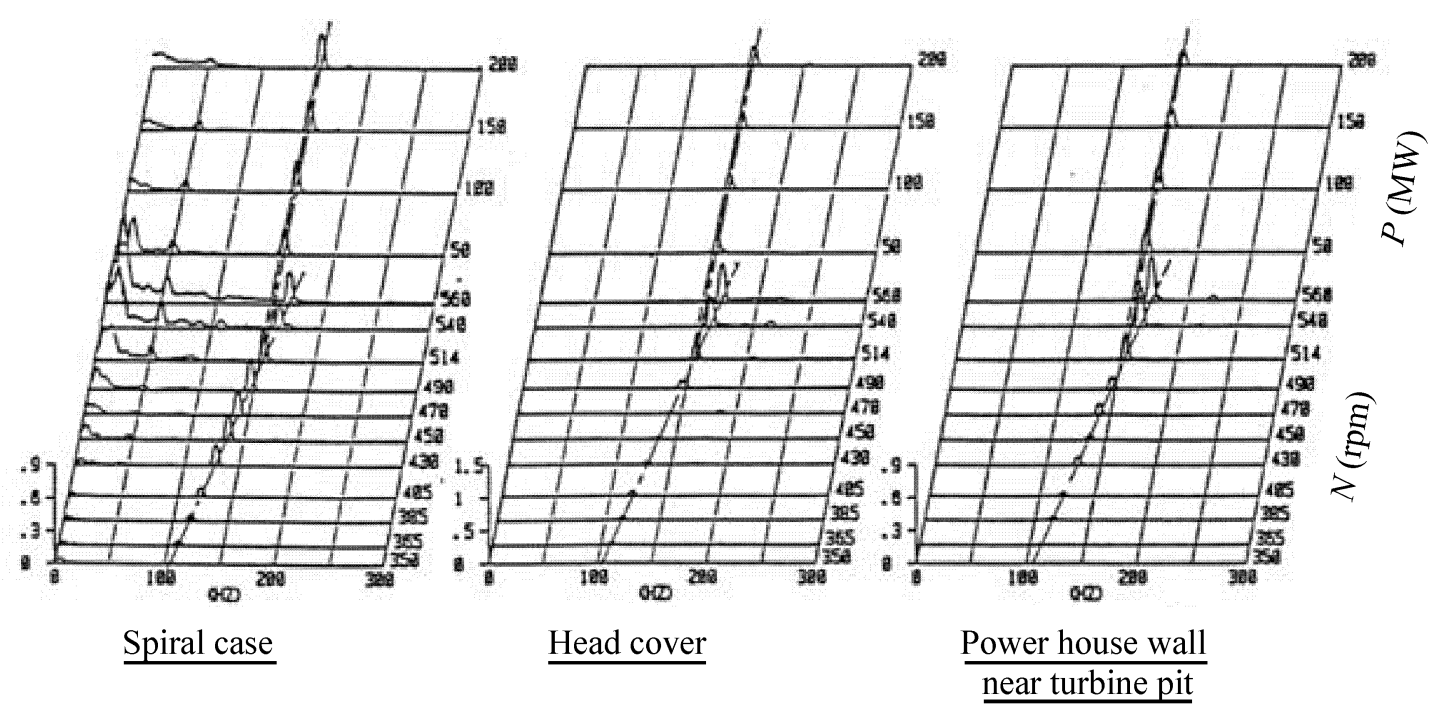

(b) Acceleration of vibrations (G)

$$
\begin{aligned}
& \text { Rated turbine output } P=207 \mathrm{MW} \\
& \text { Rated speed } \begin{array}{rl}
N & =514 \mathrm{rpm} \\
Z_{r}=6 & 3 Z_{r} \cdot N=154 \mathrm{~Hz} \\
4 Z_{r} \cdot N & =206 \mathrm{~Hz}
\end{array}
\end{aligned}
$$

Fig. 20 Spectra of pressure fluctuation and vibration measured at various locations of the stationary parts 
In this example with $Z_{g}=20$ and $Z_{g}=6,\left(3 \cdot Z_{g} \cdot N\right) \mathrm{Hz}$ corresponding to 2 diametrical node mode is most commonly observed throughout the stationary parts. In some areas, $\left(4 \cdot Z_{g} \cdot N\right) \mathrm{Hz}$ corresponding to 4 diametrical node mode is also observed.

Such selective response of a structure depends on how close the natural frequency and the normal mode of the structure coincide with those of the hydraulic excitation.

\section{Structural Design of High Head Pump-turbine Runner}

Even in case of very high head pump-turbines, if the combination of $Z_{g}$ and $Z_{r}$ can be selected as stated in paragraph 6 , the dynamic response of the runner to the hydraulic excitation can be minimized and the alternating stress of the runner may be controlled below the safety limit. However, sometimes it is difficult to select a suitable combination because of certain reasons of structural design or manufacturing. In such case, it becomes necessary in design stage to assess the dynamic response of the runner and the magnitude of alternating stress developed by it.

Because of the difficulty to calculate numerically the added mass effect or the damping effect accurately, it is emphasized that the natural frequency of the runner in water or the amplification factor of the dynamic response of the runner to the hydraulic excitation should be determined experimentally by utilizing a prototype head model test.

High operating heads inevitably lead to high stress of the runner. Therefore, development of a new material having higher tensile strength and higher fatigue limit is undoubtedly a solution for the problem of high head machines. However, if a high head pump-turbine runner is designed properly considering its dynamic behavior, the magnitude of the alternating stress of runner may be maintained within the allowable limit of the present materials.

Figure 21 shows the outline of relationship between the allowable size of defects and its depth from the surface, which is calculated by the theory of fracture mechanics for various levels of alternating stress. Considering the available sensitivity of various methods of non-destructive examination, the minimum detectable size of material defect is practically thought to be 1 or 2 mm on surface and 3 to $4 \mathrm{~mm}$ or more in sub-surface layer. Hence, the allowable amplitude of alternating stress is thought to be $\pm 40 \mathrm{MPa}$ or less for the present materials like $13 \% C_{r}-4 \% N_{i}$ or $17 \% C_{r}-4 \% N_{i}$ stainless steel.

Studies conducted in these years revealed that the alternating stress amplitude could be kept within the allowable limit even if the operating head is in excess of 800 meters.
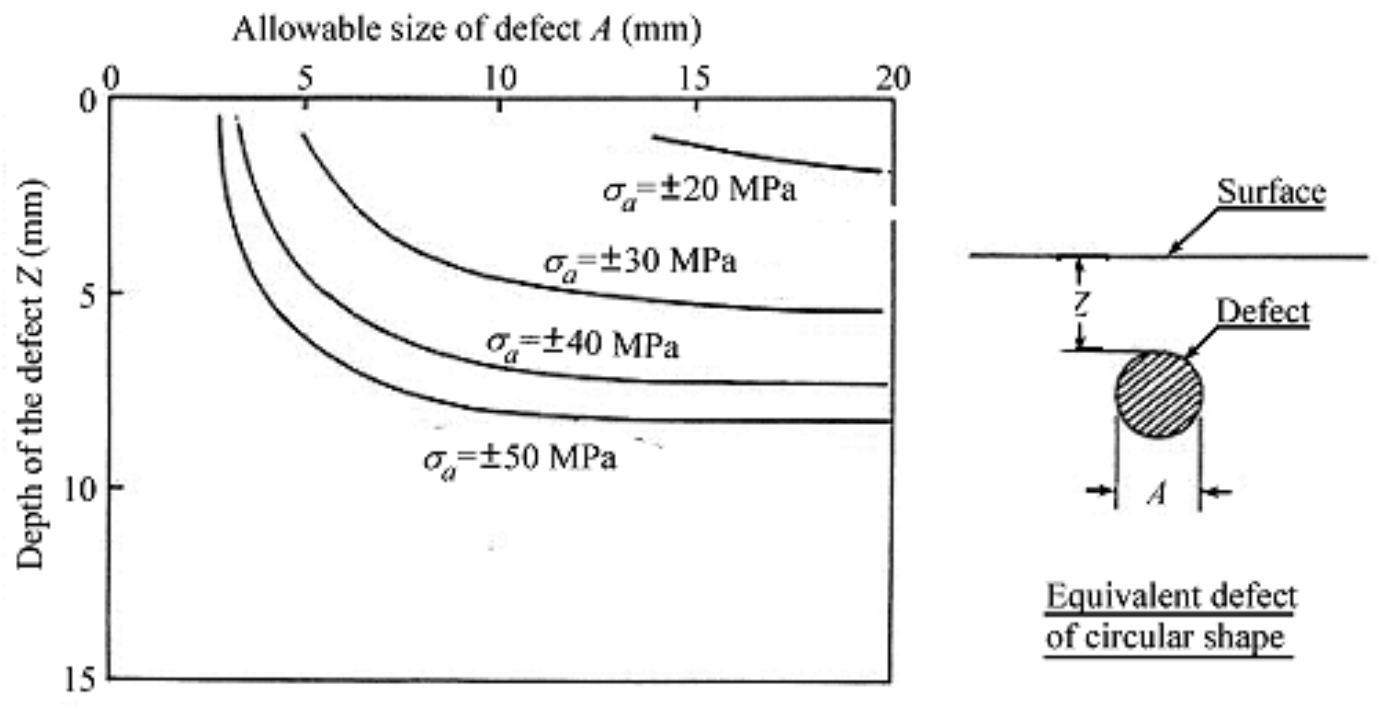

Equivalent defect of circular shape

Fig. 21 Allowable size of the material defects given by the theory of fracture mechanics

\section{Conclusion}

Based on the experiences with many high head pump-turbines and the prototype head model testing, the dynamic behavior of the high head pump-turbine runners and the problem of their alternating stress have been explored. As conclusions, the followings become evident.

(1) The hydraulic excitation force is developed by the interference of blade cascades and its frequencies, modes and intensity are determined specifically by the combination of the number of runner blades $Z_{r}$ and the number of guide vanes $Z_{g}$.

(2) Particular mode of vibration is excited among various normal modes of a runner, depending on the mode of the hydraulic excitation force.

(3) Natural frequencies of a runner are reduced considerably by the effect of the surrounding water, when it is installed in the machine.

(4) If a runner is designed properly considering the above dynamic behavior, a single stage runner made of the present material as $13 \% C_{r} 4 \% N_{i}$ stainless steel will be operable safely under operating heads exceeding 800 meters.

\section{Acknowledgments}

The author wishes to thank Professor S. Pejovic and the organizing Committee of IAHR Symposium 1990 in Beograd for their generosity to grant me to deliver this article in the special session. Also the author would like to thank our colleague for their laborious work exerted in these years which has contributed greatly to clarify this problem. 


\section{Author's Closure for Republication}

This paper was originally presented at the 15th IAHR Symposium - 1990 as a Special Lecture and the whole paper was published in the Special Book of the Symposium. Since the Special Book was not a regular Proceedings of the Symposium, it was hardly available. Considering this, Professor Y. Tsujimoto of Osaka University, one of the Editors in Chief of International Journal of Fluid Machinery and Systems (IJFMS), advised the author recently to publish this paper again on IJFMS.

The author would like to express his sincere gratitude to Professor Tsujimoto for his kind advice and to all the Editors in Chief of IJFMS for their kind favor to grant republication of this paper.

Several high head pump-turbines with the maximum pumping head ranging from $500 \mathrm{~m}$ to 700 $\mathrm{m}$ were designed later by reflecting the knowledge obtained by the research work reported in this paper.

The vibration stresses of the runners of these pump-turbines were measured at site and shown on Figure 22. It shows that their amplitude was sufficiently lower than those designed before.

Based on these achievements, $700 \mathrm{~m}$ class high head pump-turbines have been designed and installed at Kazunogawa Pumped Storage Power Plant (max. pumping head $=778 \mathrm{~m}$, max. turbine output $=412 \mathrm{MW}$ ) and Kan'nagawa Pumped Storage Power Plant (max. pumping head $=728 \mathrm{~m}$, max. turbine output = $482 \mathrm{MW}$ ). They were commissioned in 1999 and in 2005; respectively. Since then, they have been operated without any problem.

Thus the studies reported in this paper could contribute to the enhancement of the reliability of very high head pump-turbines.

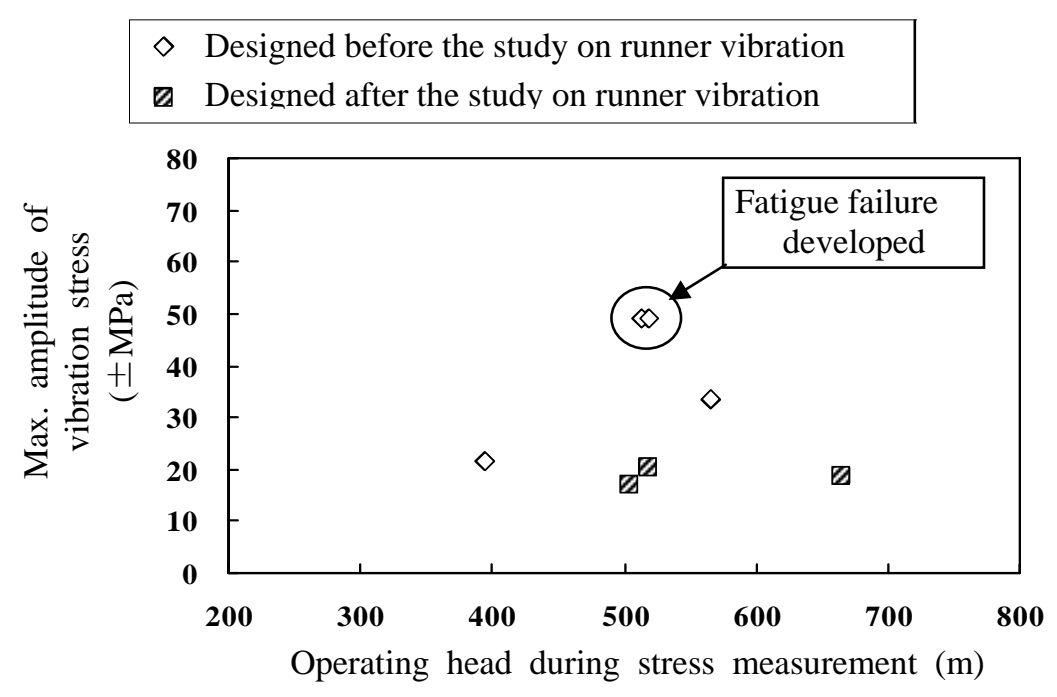

Fig. 22 Vibration stress of runners reduced by the study

\section{Nomenclature}

$D \quad$ Reference diameter of runner

$D_{0} \quad$ Diameter of runner

$\mathrm{S} \quad$ Scale ratio of the model, $=\left(D / D^{\prime}\right)$

$E \quad$ Young's modulus of the material

$f_{h} \quad$ Frequency of hydraulic excitation

$F_{i} \quad$ The force imposed by $Z_{g}$ guide vanes on one particular $i$-th runner blade $(i=1,2,3 \cdots)$

$f_{n} \quad$ Natural frequency

$f_{r} \quad$ The frequency of the n-th harmonic of the hydraulic excitation exerted on runner due to the interference

$v$

$X_{1} \quad$ One vibration mode having $k_{1}$ diametrical nodes

with progressive wave form

$X_{2} \quad$ The other vibration mode having $k_{2}$ diametrical nodes with retrogressive wave form

$\begin{array}{ll}m, n & \text { Arbitrary integers } \\ Z_{g} & \text { The number of guide vanes }\end{array}$

$Z_{r} \quad$ The number of runner blades

$\delta$

$\phi$

$\phi_{i}$ excitation or vibration

$k_{1} \quad$ The lowest number of diametrical nodes with progressive wave form

$k_{2} \quad$ The lowest number of diametrical nodes with retrogressive wave form

$N \quad$ Rotational speed of runner [rps]

$R(i) \quad$ The $i$-th blade

$S(j) \quad$ The $j$-th guide vane
Axial distance between head cover and runner Angular coordinate fixed to runner

Angular coordinate of the location of the blade $R(i)$ on the coordinates fixed to runner

Location of the guide vane $S(j)$ on the stationary coordinate

Density of the material

Values for the model while those without prime are for the prototype.

\section{References}

[1] Kubota, Y., Suzuki, T., Tomita, H., Nagafuji, T., Okamura, C., 1983, "Vibration of Rotating Disc Excited by Stationary Distributed Forces,” JSME Proc. Vol. 49, No. 439-C, pp. 307-313. (in Japanese)

[2] Yamagata, I., Internal Report of Toshiba.

[3] Kubota, Y., “Added Mass Effect of Water on vibrating Circular Discs in Water,” Proc. of JSME Symp. on Mech. Dynamics, No. 83-0011. (in Japanese)

[4] Tsunoda, S. and Yamagata, I., Internal Report of Toshiba.

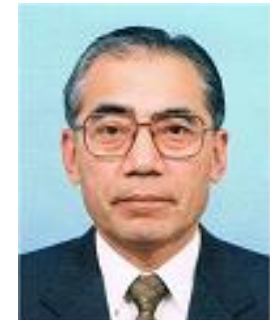

Hiroshi Tanaka Graduated from the University of Tokyo in 1956. Then joined Hydraulic Turbine Department of Toshiba Corporation and engaged in R\&D work on hydraulic turbines; especially, on the development of pump-turbines. Since 1965, engaged in hydraulic design of large capacity high head pumpturbines and preparation of the technical proposals for many high head pumped storage projects in the world. In 1987, became Chief Engineer in charge of Hydraulic Machinery to supervise all R\&D, design and manufacturing of hydraulic turbines in Toshiba. In 1993, retired from Toshiba and became Technical Advisor to Toshiba until 2000. Now working as an independent consultant on hydraulic machinery. 